Document downloaded from:

http://hdl.handle.net/10251/62777

This paper must be cited as:

De Luca, F.; Verderame, GM.; Gómez Martínez, F.; Pérez García, AJ. (2014). The structural role played by masonry infills on RC building performances after the 2011 Lorca, Spain, earthquake. Bulletin of Earthquake Engineering. 12(5):1999-2026. doi:10.1007/s10518-0139500-1

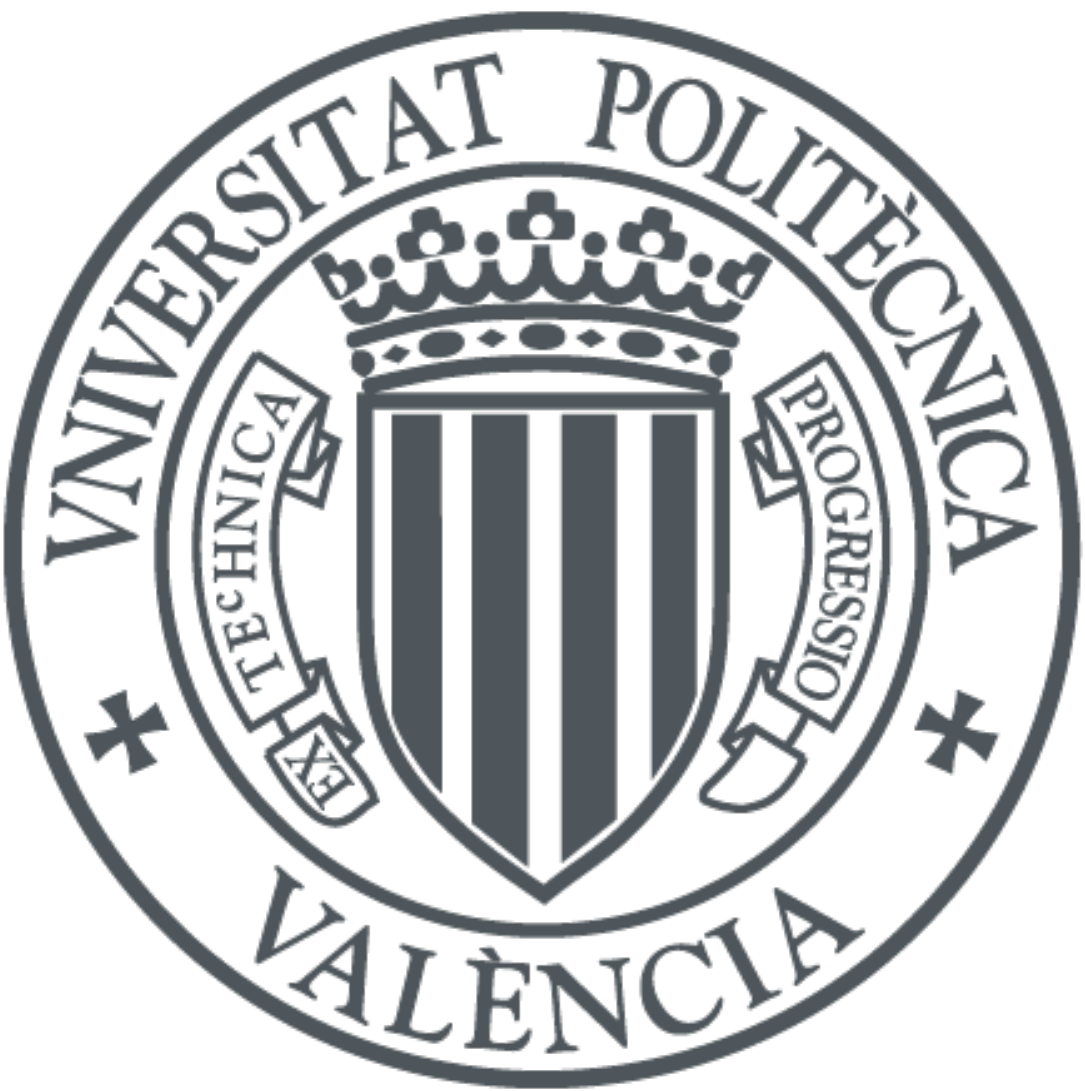

The final publication is available at

http://dx.doi.org/10.1007/s10518-013-9500-1

Copyright Springer

Additional Information

The final publication is available at Spriger via http://dx.doi.org/10.1007/s10518-013-9500-1 


\title{
THE STRUCTURAL ROLE PLAYED BY MASONRY INFILLS ON RC BUILDING PERFORMANCES AFTER THE 2011 LORCA, SPAIN, EARTHQUAKE ${ }^{*}$
}

\author{
Flavia De Luca ${ }^{\dagger}$, Gerardo M Verderame \\ Department of Structure for Engineering and Architecture - DiSt, University of Naples Federico II, \\ Via Claudio, 21, 80125 Naples
}

\section{Fernando Gómez-Martínez, Agustín Pérez-García}

Department of Mechanics of the Continuum Media and Structural Theory, Polytechnic University of Valencia, Camino de Vera, s/n, 46022 Valencia, Spain

\begin{abstract}
On May 11, 2011 an earthquake of magnitude $5.1\left(M_{w}\right)$ struck Murcia region causing 9 casualties and damage to buildings and infrastructures. Even if the main characteristics of the event would classify it as a moderate earthquake, the maximum PGA registered (equal to $0.37 \mathrm{~g}$ ) exceeded significantly local code provisions in terms of hazard at the site. The latter was a result of directivity effects in the near source region. An overview of earthquake characteristics and damage observed is provided. Notwithstanding the lack of proper structural design characterizing building stock in the area, most of the losses were caused by non-structural damage. According to in field observations, it emerges that masonry infills provided additional, "not designed", strength to reinforced concrete buildings. Observed damage data, collected after the earthquake, are shown and compared to the results of a simplified approach for nonstructural damage assessment of RC infilled structures (FAST vulnerability approach). The latter comparison provided a fair accordance between observed data and analytical results.
\end{abstract}

KEYWORDS: Lorca earthquake, infills, damage states, nonstructural damage assessment, FAST vulnerability approach

\section{INTRODUCTION}

Most of the experience regarding the early earthquake engineering was collected after disastrous earthquakes in seismically prone areas in the world, such as Japan (Edo, 1855), California (San Francisco, 1906) and Italy (Messina, 1908). In the last decades earthquake engineering has progressed towards quantitative and probabilistic assessment frameworks (e.g., performance based earthquake engineering) for the control of seismic risk and, more in general,

\footnotetext{
* Based on a short paper presented at the $15^{\text {th }}$ World Conference on Earthquake Engineering, Lisbon, Portugal, September 24-28, 2012.

† Corresponding author: flavia.deluca@unina.it
} 
towards the reduction of losses induced by earthquakes (i.e., Cornell and Krawinkler, 2000; Krawinkler and Miranda, 2004). Notwithstanding the huge efforts of recent years in this field, seismic events still represent the real benchmark to improve the tools already available for practitioners.

Thanks to damage surveys after earthquake events in the last decade (e.g., Rossetto and Peiris 2009, Ricci et al. 2011a), it was observed that reinforced concrete building performances can be significantly increased or conversely significantly decreased in comparison to the design targets met according to code provisions at the time of construction. The latter observation emphasizes the "structural" role played by "non structural" elements such as masonry infills. Recent studies have been aimed at the quantification of infill structural role (e.g., Dolšek and Fajfar 2001, 2004, 2005) towards the final enhancement of a proper consideration of these elements within code provisions. On the other hand, infills' characteristics can be significantly different according to the region in which they are realized; thus, it is hard to quantify their structural role unless a detailed macro-modeling approach is carried out (e.g., De Luca 2012, Verderame et al. 2011). Luckily, Mediterranean countries have in common the basic building practice rules and, regarding infill structural contribution, general conclusions can be still draw out, enjoying the results of experimental data and in field campaigns form previous studies.

A simplified damage assessment procedure (FAST vulnerability approach) for infilled reinforced concrete structures is carried out, and observed damage data, collected after the $11^{\text {th }}$ May 2011 Lorca earthquake, are employed as benchmark for its validation. This tool can represent a reliable way for a first damage mapping in the phase of emergency management right after seismic events (e.g., Goretti and Di Pasquale, 2006). The approach belongs to the wider family of vulnerability assessment methodologies based on spectral displacements (e.g., NIBS 1997, 1998, 2002; Kircher et al., 1997; Erdik et al., 2004, among others) in which damage states are classified according to the 1998 European Macroseismic Scale (Grunthal, 1998). FAST method has been also applied on Italian data collected after the recent Emilia 2012 earthquake (Verderame et al., 2012, Manfredi et al., 2013), providing satisfactory results.

Aimed at a comprehensive evaluation of the case study event considered, a general overview of earthquake seismological characteristics is provided, (Section 2). The evolution of Spanish design codes and its effect on Lorca building stock are analyzed, (Section 3). Then, main structural and non structural damage data are shown and analyzed in the light of building stock 
characteristics (Section 4). Finally FAST damage assessment procedure for infilled reinforced concrete structures is described and applied to the case of Lorca earthquake, (Section 5).

\section{CHARACTERISTICS OF THE EVENT}

On $11^{\text {th }}$ May 2011 at 16:47:25 an earthquake of magnitude $M_{w}=5.1$ struck Murcia region (IGN 2011); the epicenter was $2 \mathrm{~km}$ far from the city of Lorca (3km from the seismic station). This was the third largest earthquake recorded by strong-motion instruments in Spain since 1951. The mainshock succeeded an important foreshock of magnitude $M_{w}=4.5$, occurred at 15:05:13, nearly in the same place ( $3.5 \mathrm{~km}$ from Lorca seismic station), see Figure 1. Focal mechanism was strike slip with low inverse influence (Figure 1a).
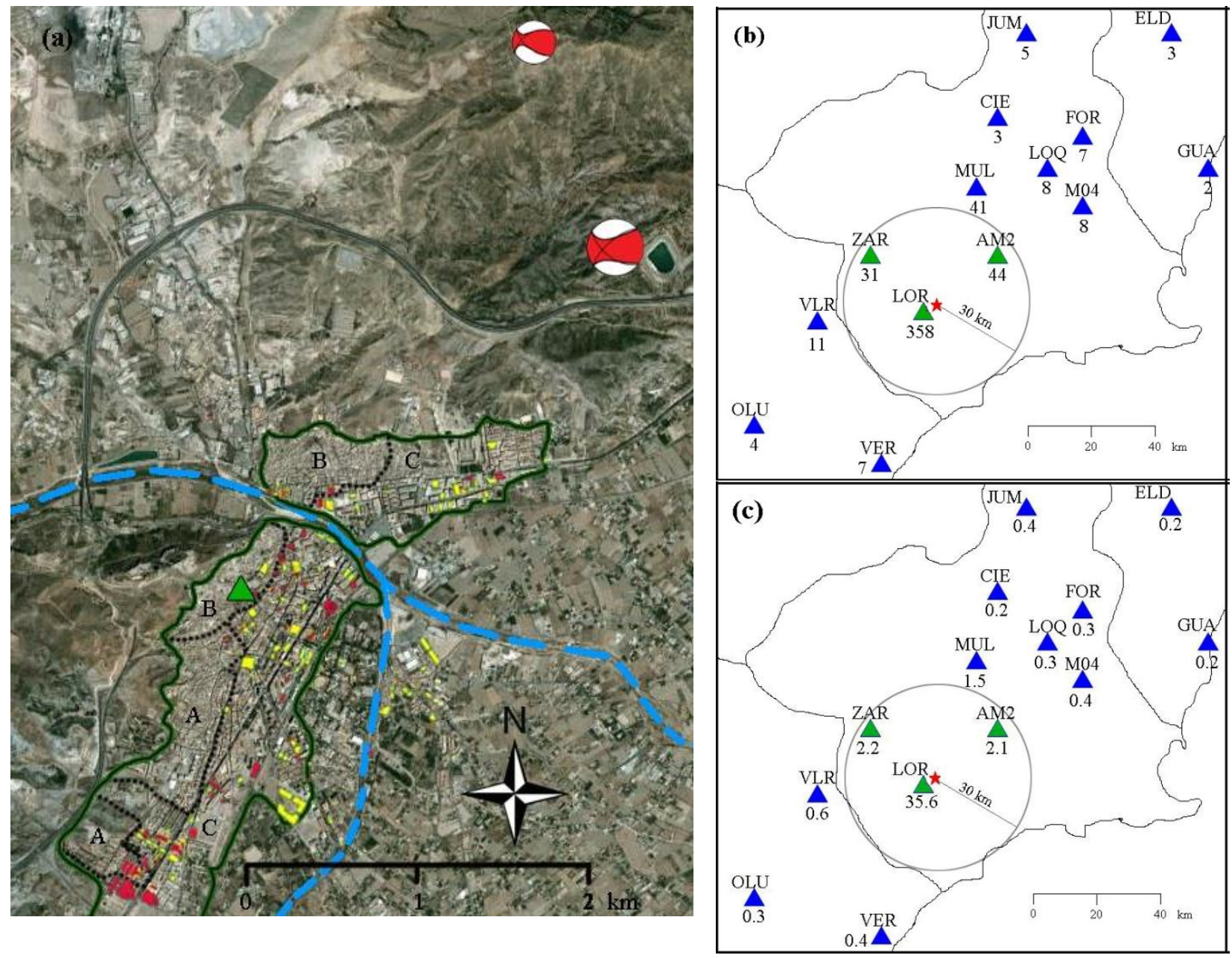

Figure 1. Lorca: river Guadalentín (discontinuous blue line), limit of the constructed area (green-black line), limits of different soil types (EC 8 classification, black dotted line), LOR seismic station (green triangle), mainshock and foreshock epicenter (big and small beach balls, respectively), high (red) and medium (yellow) damaged buildings as classified in the on-site damage survey (a); PGA in $\mathrm{cm} / \mathrm{s}^{2}$ (b) and $\mathrm{PGV}$ in $\mathrm{cm} / \mathrm{s}(\mathrm{c})$ measured at the different stations. 
Proximity to the epicenter and low hypocenter depth (2-4 km for both events), caused very high macro seismic intensities in Lorca for such moderate event. Macrosesimic intensities were VI for the foreshock and VII for the mainshock, respectively (Cabañas et al. 2011).

\subsection{General considerations}

The main earthquake was registered by 17 stations located from 3 to $185 \mathrm{~km}$ from the epicenter. Lorca station (LOR) was the nearest one, placed on B soil type, (see Figure 1). At this station maximum PGA was equal to $0.367 \mathrm{~g}$ for mainshock NS component, and the same component was equal to $0.289 \mathrm{~g}$ for the $\mathrm{M}_{\mathrm{w}} 4.5$ foreshock. The maximum PGA value registered during the mainshock is more than three times higher than the design PGA provided by codes for this soil type (equal to $0.124 \mathrm{~g}$, see section 5.1 ) and has $0.01 \%$ probability of being exceeded in 50 years (RISMUR 2006); 1000 times lower than the conventional, code based, 10\%. On the other hand, according to new probabilistic seismic hazard studies, performed before the $11^{\text {th }}$ May event, an increment from $0.12 \mathrm{~g}$ to $0.19 \mathrm{~g}$ was suggested for Lorca code acceleration (on hard soil type) (Mezcua et al. 2011). Furthermore, it is worth to observe that the event was characterized by a significant attenuation of PGA and PGV with the distance, as shown in Figure 1b and 1c.

Horizontal elastic spectra of the foreshock and the mainshock are shown in Figure 2 for the three closest stations -Lorca (LOR), Zarcilla de Ramos (ZAR) and Alhama de Murcia (AM2). LOR, ZAR, and AM2 stations where characterized, in the case of mainshock event, by increasing epicentral distance, 3.0, 24.6 and 25.9km, respectively, see Figure 1. Signals have been filtered and corrected according to the same criteria employed in Chioccarelli et al. (2009).
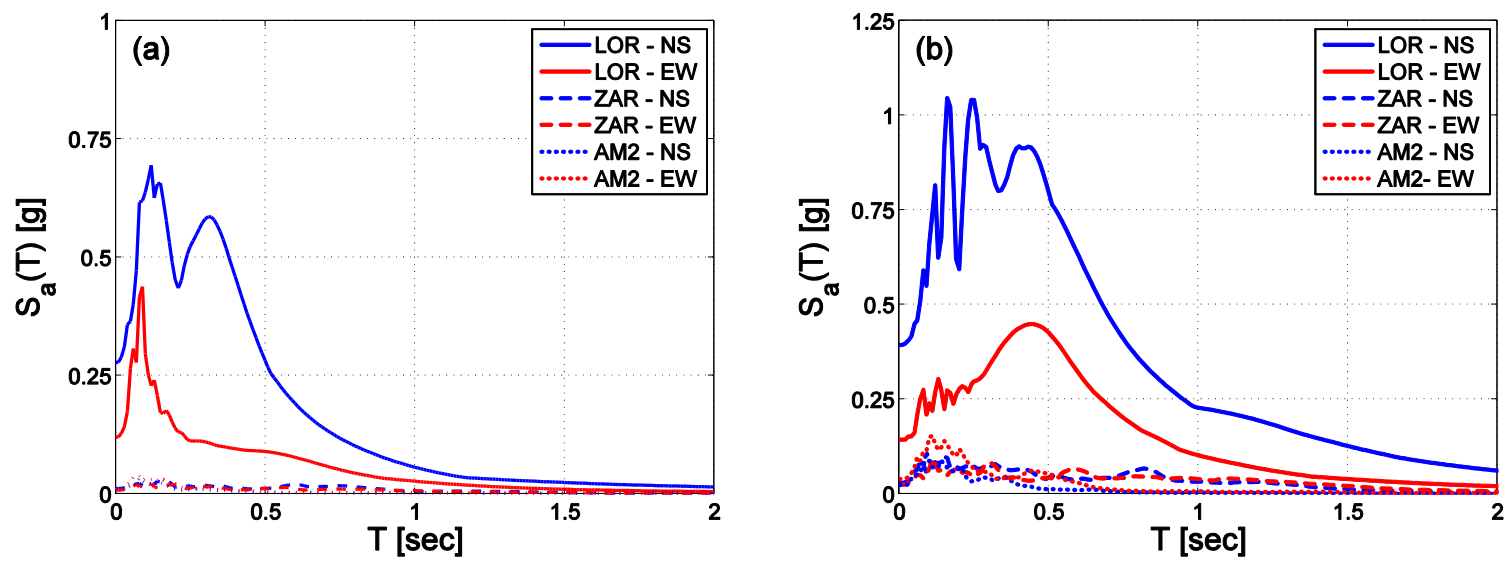

Figure 2. Elastic response spectra from the signals registered in LOR, ZAR and AM2 stations, closer than $30 \mathrm{~km}$ to the epicenter, for foreshock (a) and mainshock (b). 
Main ground motion characteristics in Lorca station (Table 1) show a significant difference between NS and EW components. Low depth of the event and near fault location of LOR station are the causes of the high values of peak strong motion parameters (PGA and PGV) compared with the relative low values of integral strong motion parameters, such as $5-95 \%$ significant duration $\left(S_{D}\right)$, Arias Intensity $\left(I_{A}\right)$, Housner Intensity, and the so called Cosenza and Manfredi index $\left(I_{D}\right)$. Small values for $I_{D}$ are typical for impulsive earthquakes, (Manfredi 2001). In fact $I_{D}$ can be assumed as an indicator of cyclic demand of earthquakes (Manfredi 2001; Iervolino et al. 2010); low values indicate that most of the energy of the earthquake is dissipated by structures in a small number of cycles.

Table 1. Foreshock and mainshock peak and integral strong motion parameters at Lorca station (LOR).

\begin{tabular}{|l|l|l|l|l|l|l|}
\hline & \multicolumn{3}{|l|}{ Foreshock (Lorca station - LOR) } & \multicolumn{3}{l|}{ Mainshock (Lorca station - LOR) } \\
\hline Direction & N-S & E-W & V & N-S & E-W & V \\
\hline PGA $(\mathrm{g})$ & 0.289 & 0.128 & 0.075 & 0.367 & 0.153 & 0.117 \\
\hline PGV $(\mathrm{cm} / \mathrm{s})$ & 12.9 & 4.1 & 2.3 & 35.6 & 14.2 & 8.0 \\
\hline$I_{A}(\mathrm{~cm} / \mathrm{s})$ & 14.0 & 2.5 & 1.6 & 52.7 & 10.9 & 4.5 \\
\hline$S_{D}(\mathrm{~s})$ & 0.535 & 1.85 & 1.82 & 1.01 & 3.395 & 3.28 \\
\hline$I_{D}$ & 2.403 & 3.123 & 5.882 & 2.571 & 3.208 & 3.081 \\
\hline Housner intensity $(\mathrm{cm})$ & 22.941 & 7.598 & 5.757 & 78.012 & 31.698 & 24.537 \\
\hline
\end{tabular}

\subsection{Directivity effects}

Aimed at the quantitative classification of directivity effects, the record registered at Lorca station during the mainshock event was rotated according to parallel (FP) and normal (FN) directions of Alhama fault $\left(\right.$ strike $\left.=230^{\circ}\right)$. In Figure 3 acceleration, velocity and absolute and relative energy input elastic spectra of the rotated components are shown for $\xi=0.05$, where $\xi$ is the fraction of critical damping. The energy input spectra in Figure $3 \mathrm{c}$ and $3 \mathrm{f}$ are expressed in form of equivalent velocity $\left(V_{E}\right)$ according to the same definition given in Uang and Bertero (1990). The significant difference between relative and absolute $V_{E}$ represents a proxy for directivity effects. The presence of pulses generates smaller or larger relative energy magnitude in the short and long period ranges, respectively, with respect to absolute energy (Kalkan and Kunnath 2008).

The spectra in Figure 3a, $3 \mathrm{~b}$ and $3 \mathrm{~d}$, 3e allow the evaluation of $T_{C}$ and $T_{D}$ periods delimiting the constant velocity branch of the spectra according to the procedure described in Lam et al. (2000). $T_{C}$ and $T_{D}$ periods are equal to $0.48 \mathrm{~s}$ and $0.57 \mathrm{~s}$ for FN component and equal to $0.24 \mathrm{~s}$ and 
0.88s for FP component. The pseudo velocity spectrum for the normal-fault component of the record shows a very short stretch of constant velocity value (see Figure 3b), typical of the impulsive motions (Chopra 2007).

Indeed, the quantitative method by Baker (2007), based on wavelet analysis, confirmed the nearfault impulsive characteristics already suggested by the spectra in Figure 3. The period of the velocity pulse is an important parameter for structural engineers. No well-defined concept of periods exists for wavelets such as there is for sine waves in Fourier analysis, but the period associated with the maximum Fourier amplitude of a wavelet can be used to define a pseudo period $\left(\mathrm{T}_{\mathrm{P}}\right)$. According to Baker's classification a pulse-like record meets all the following three criteria:

1. The pulse indicator value is greater than 0.85 .

2. The pulse arrives early in the time history.

3. The original ground motion has a PGV of greater than $30 \mathrm{~cm} / \mathrm{sec}$.
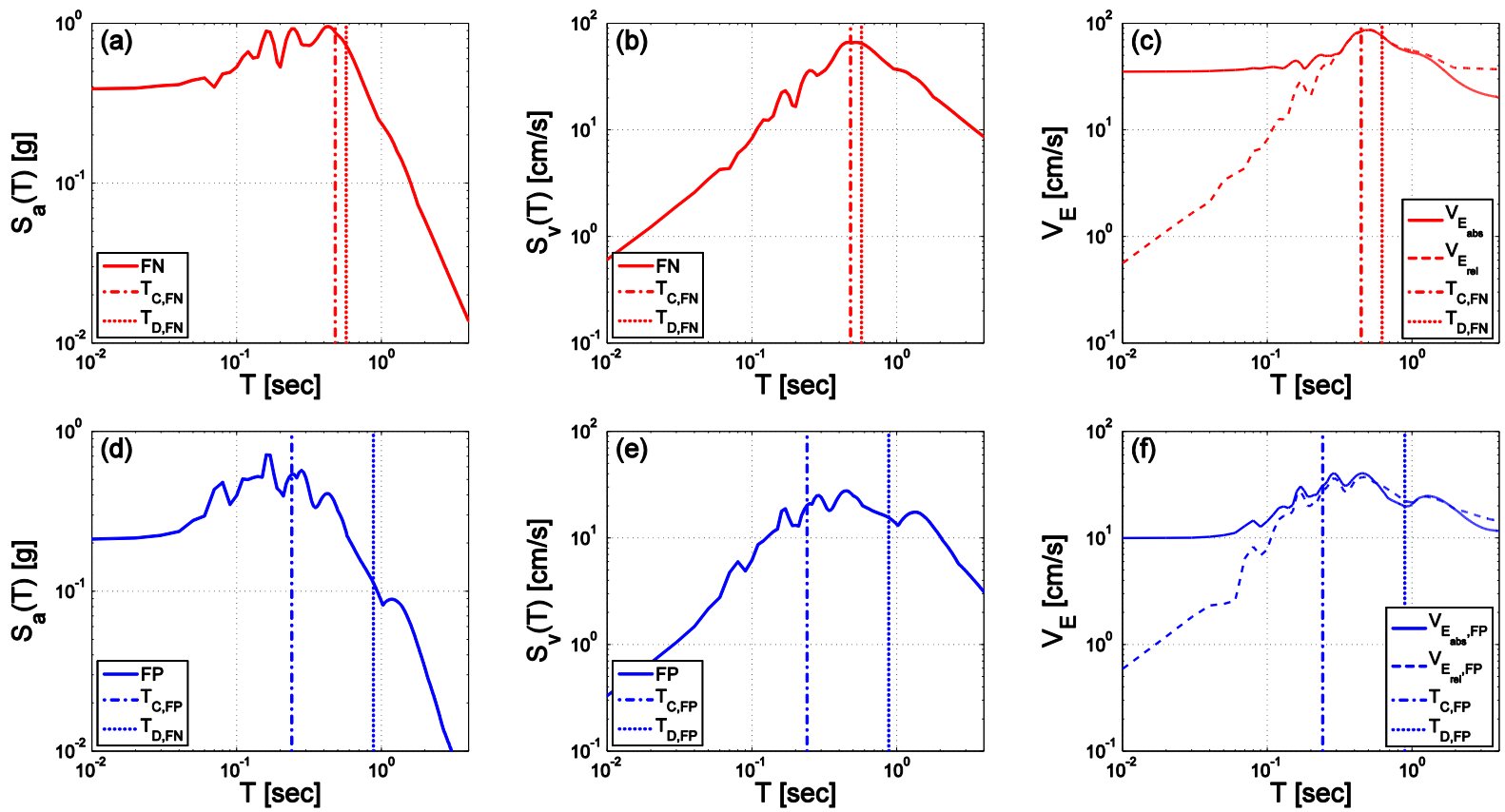

Figure 3. Acceleration, velocity, and relative and absolute energy in terms of equivalent velocity spectra for fault normal FN (a), (b), (c), and fault parallel FP, (d), (e), (f) mainshock signals registered in Lorca (LOR) station with the evaluation of $T_{C}$ and $T_{D}$.

For FN component at Lorca station, Baker's pulse indicator is equal to $0.99, \mathrm{~T}_{\mathrm{P}}$ is equal to $0.68 \mathrm{~s}$ and the component is classified as pulse-like (see Figure 4a); while for FP components pulse indicator is equal to $0.03, \mathrm{PGV}$ is $9.97 \mathrm{~cm} / \mathrm{s}$ and the record is not classified as pulse-like (see Figure $4 b)$. 
(a)

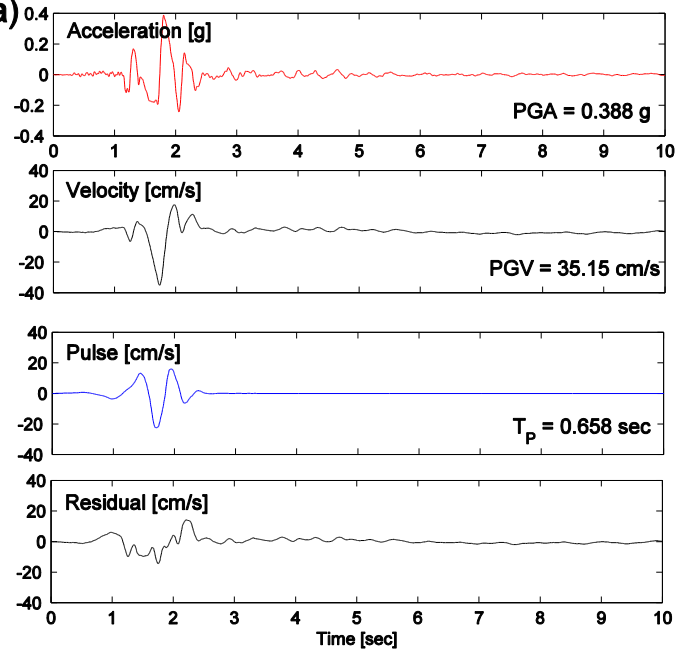

(b)

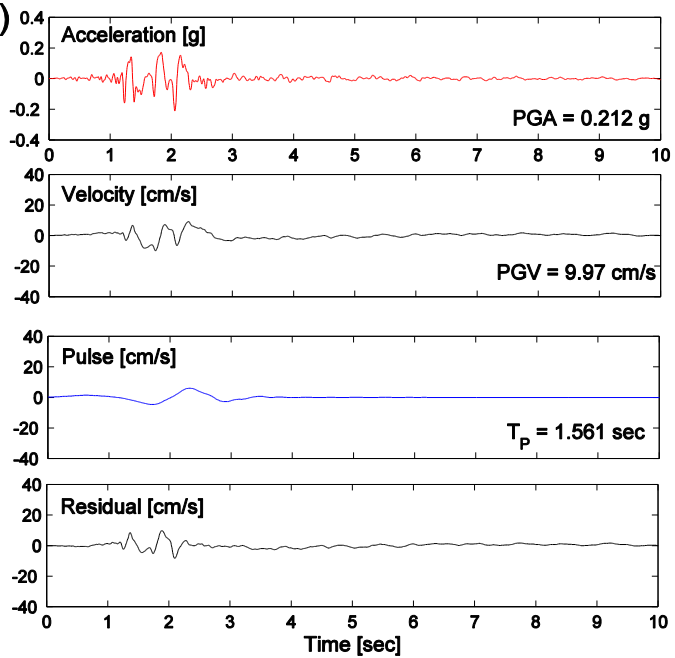

Figure 4. Baker (2007) quantitative classification of fault normal (FN) (a), and fault parallel (FP) (b) mainshock signals registered at Lorca (LOR) station, characterized by pulse indicators equal to 0.99 and 0.03 , respectively.

\section{COMMON DESIGN PRACTICE FOR RC BUILDING IN LORCA}

Aimed at a proper characterization of the building stock in Lorca, data from Feriche et al. (2012) and Cabañas et al. (2011) were crossed. Results show that $77 \%$ of the buildings are masonry structures and the other $23 \%$ are modern frames (Cabañas et al. 2011), mainly RC. In Figure 5a the distribution in terms of number of storeys is shown. Storeys' data are not specialized for structural typology (e.g., masonry, $\mathrm{RC}, .$. ). Therefore, it has been made the assumption that buildings with no more than two storeys are all masonry, so covering $68 \%$ of the total building stock, while three storey buildings are equally distributed between masonry and RC, dealing to the above $77 \%$ of masonry structures on the whole building stock, (see Figure 5a).

According to the above assumptions it can be inferred that RC buildings in Lorca are mainly characterized by a number of storeys between 3 and 5 .

In Figure $5 \mathrm{~b}$ data on the age of construction are crossed with the year in which the different seismic codes have been released in Spain. Assuming that masonry buildings have been realized before RC buildings, it can be inferred that most of RC buildings had been designed according to codes PDS-1 (1974), NCSR-94 (1994) and NCSE-02 (2002).

Since the first reference to seismic actions was made in a code, MV-101 (1962); four seismic codes have been released in Spain. Spanish codes released since 1962 can be classified in two groups: "old codes" PGS-1 (1968) and PDS-1 (1974) and "new codes" NCSR-94 (1994) and NCSE-02 (2002). Old codes measure the hazard in terms of MSK intensity level. They only 
provide lateral load (linear static) analysis, and they do not consider explicitly either behavior factor $(q)$ or capacity design criteria. New codes measure the hazard in terms of elastic spectral acceleration and accounts for ductility in the design. Notwithstanding the significant enhancements with respect to old codes, new codes still have significant lacks if compared with Eurocode 8 (CEN 2004). As an example, there are no quantitative rules for capacity design in beams, columns, and beam-column joints. Specific quantitative prescriptions are only provided in the case of squat columns as optional recommendations. Structural and especially nonstructural irregularities in elevation are not taken into account, neither by means of a behavior factor reduction, nor by a magnification of the action in the potential soft storey. Furthermore, upper limits of compression in columns and drift limitations are not regulated. Nevertheless, the last released RC code, EHE-08 (2008), recommends the use of capacity design and it is very close to the prescriptions of Eurocode 8 (or EC8) provisions (CEN 2004). Conception of buildings, up to 2008, in Spain, did not follow the basic seismic provisions or construction rules normally adopted in seismically prone regions. Even if they are considered not suitable for earthquake resistant design, wide beams and flat slabs, classified as low-ductility structural design $(q=2)$, are still a common design practice. Low ductile slab arrangements (mainly wide beams and joists, and waffle slabs or solid slabs) are the most common building solutions for RC structures in all the country and in Murcia region (Benavent-Climent, 2007; Benavent-Climent et al., 2008; Vielma et al., 2010). Very few structures are characterized by frame in both principal directions.

Moreover, given the severe deflection limitations provided by previous RC design codes (EHE 1999), equal to $1 \mathrm{~cm}$ for active deflection; slabs usually got oversized, thus leading to the absence of capacity design, not sustainable in the case of very thick slabs. RC shear walls are seldom employed as structural scheme, so hollow or semi-solid brick masonry infilling panels (the most common solution for façades, internal divisions and lift or stair cases) play a significant role in the initial lateral stiffness and strength of the structures. The latter is a typical characteristic of all building stocks in the Mediterranean area. Furthermore, seismically questionable design solutions, likely causing soft-storey behaviors, are quite frequent. Ground floors are often characterized by a lack of infill walls (pilotis), and columns are characterized by higher interstorey height compared to other levels, leading to a significant increase of deformability at the ground floor. Squat or captive columns are quite frequent. The above typical 
structural characteristics represent one of the main weaknesses of Spanish building stock and likely lead to structural damage when seismic events occur.
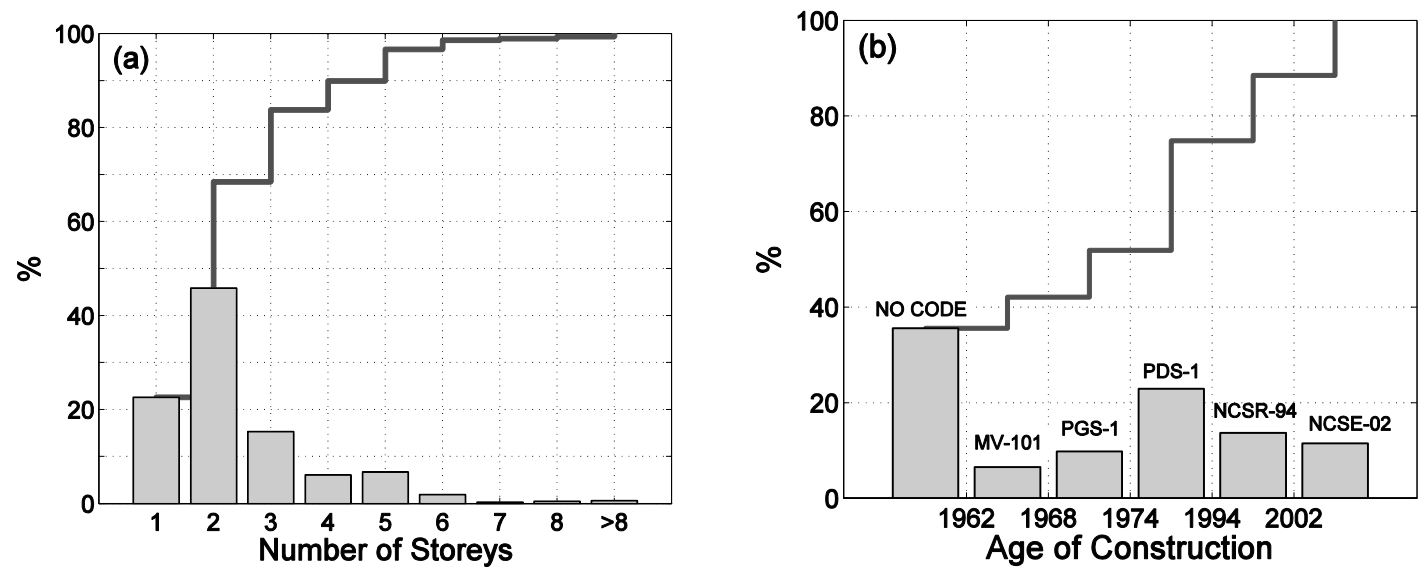

Figure 5. Frequency and cumulative distributions in Lorca building stock for: number of storeys (a), age of construction and applied code provision for the design of the building stock (b), Feriche et al. (2012).

\section{DAMAGE OBSERVED}

In this section, level, type and distribution of damage are shown. These data represent a benchmark for the results of the simplified damage assessment approach described in the next section. The level of damage, classified according to the EMS-98 damage scale (Grunthal, 1998) is shown as function of number of storeys and age of construction. Such data are then integrated with some photographic examples of structural and nonstructural damage, aimed at highlighting local features of building practice and their consequences in terms of damage observed.

\subsection{Damage data}

According to on-site damage survey after the earthquake, buildings were preliminary classified as "yellow" or "red" (see Figure 1a), depending on whether they were unsafe for use and characterized by low structural damage, or, conversely, they were characterized by significant structural damage, (Cabañas et al. 2011). Damage was not homogeneous between similar and contiguous structures. The latter can be an effect explained by directivity effects characterizing the event (see Section 2.2). On the other hand, according to data available, it is not possible to recognize whether the strong foreshock already damaged structures or induced preliminary residual drifts. 
Damage data collected after the earthquake have been classified according to the EMS-98 scale as function of number of storeys, age of construction, (Feriche et al. 2012). According to EMS-98 scale, damage can be classified in five grades, increasing with damage. The description of each damage state depends on the type of structure considered (e.g., masonry, reinforced concrete). In most practical cases $\mathrm{RC}$ frames are realized with nonstructural masonry infills. Thus, damage states refer to both structural and nonstructural damage up to grade 3 . Grade 4 and 5 are characterized by heavy and very heavy structural damage. In the following, statistics concerning RC structures were obtained by a disaggregation of the data, according to the assumptions made in section 3: RC buildings have been assumed to have three or more storeys and to be designed according to PDS-1 (1974) and subsequent codes released. Figure 6 shows damage statistics for the total building stock and RC structures. Severe structural damage was not so frequent: only $8.53 \%$ of the RC structures were classified in grade 4 and 5 , while grade 2 was very frequent. Moreover, severe structural damage in RC buildings was mainly induced by local or brittle failures. Large scale damage approaches, often discard the effect of brittle failures; thus, in the following, only the trend of damage grade up to 3 will be considered. It is worth to note that buildings that showed no damage at all had been included in damage grade 1.

According to data available in Cabañas et al. (2011), and the frequency distributions shown in Figure 6 , it can be observed that $28.5 \%$ of RC buildings were characterized by damage grades between 3 and 5, while only $19.3 \%$ of masonry structures showed damage in the same range. Regarding this difference, it was observed that the east part of the city, where most of the RC buildings are located, is characterized by $\mathrm{C}$ soil type (worse quality), and the density of damage in this area was higher. Thus, soil amplification and typical construction practice of RC buildings could represent the principal causes of the heavier structural damage observed respect to masonry structures.

In Figure 7, data for RC structures are shown as function of the number of storeys, and age of construction. Storey data are shown from 3 to 6 , since only $1.4 \%$ of the building stock has 7 or more storeys (Figure 5a). Results show that high nonstructural and low structural damage increase with the number of storeys, being the median included in the middle range of grade 2. A limited increase of non-structural damage for new codes is observed; on the other hand such an increasing trend is not significant enough to allow any general conclusion on this observation. 


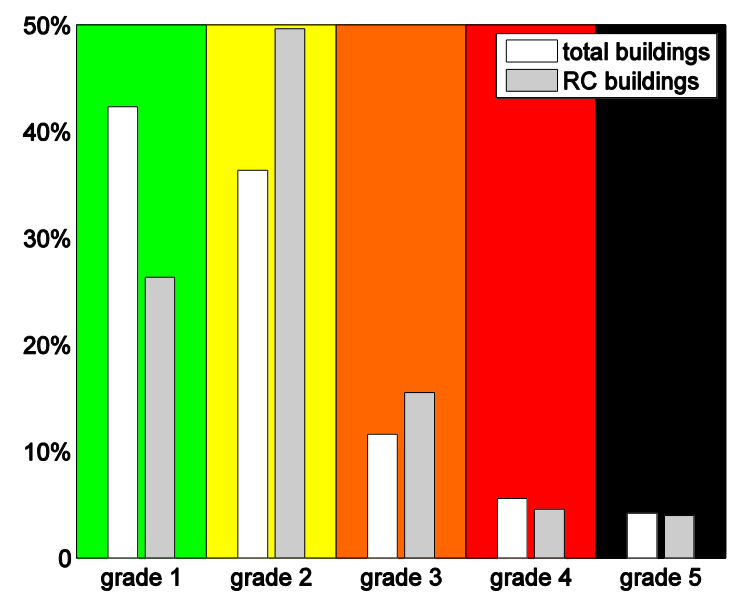

Figure 6. Frequency distribution of EMS-98 damage levels in Lorca
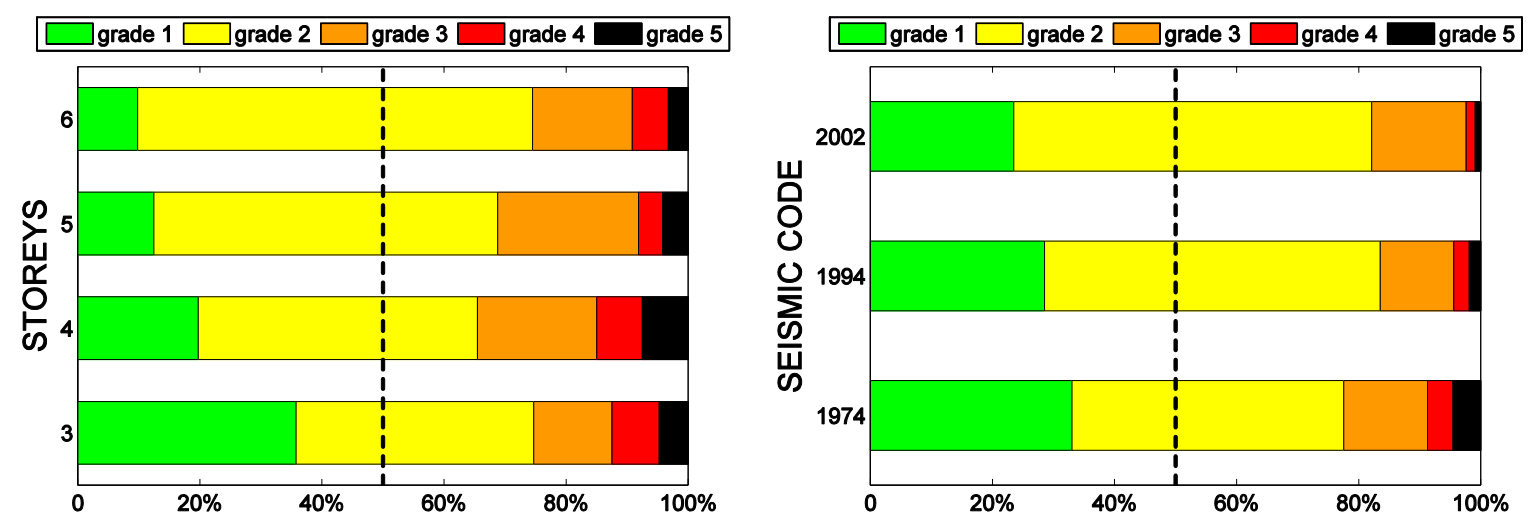

Figure 7. Frequency distribution of damage levels for RC structures depending on the number of storeys (a) and seismic code (b).

\subsection{Structural damage}

Structural damage observed during Lorca earthquake was not so frequent. However, structural damage was often a result of the lacks in code regulations. Mainly pre-emptive brittle failures at the ground floor columns, no relevant damages in beams, slabs or beam-column joints, and absence of significant residual drifts can be observed. The design approach with no capacity design and frequent irregularity in elevation did not allow the development of plastic deformations because of the occurrence of pre-emptive brittle failures or limited ductility failures (Sezen and Moehle 2004, Biskinis et al., 2004).

Shear-axial failures in columns were frequent (Figure 8). Stirrups are characterized by low diameters, not proper spacing, and $90^{\circ}$ hooks that do not confine the concrete core and reduce the 
effectiveness of the transversal reinforcement (Biskinis et al., 2004). Such lack of seismic detailing of the elements, accompanied by high longitudinal percentage ratios (see Figure 8), increases significantly the occurrence of brittle failures or limited ductility failures (De Luca and Verderame, 2013) that end up in typical shear diagonal cracking (Figure 8d) or buckling of the longitudinal reinforcement and consequent axial load collapse. Another frequent cause of damage was the brittle failure of compressed diagonal concrete strut of "squat" (Figure 9a) or "captive" columns (Figure 8d), due to the presence of RC basement walls or masonry infilling panels limiting shear span ratio. Other brittle failures observed were produced by squat columns in staircases (Figure 9b).
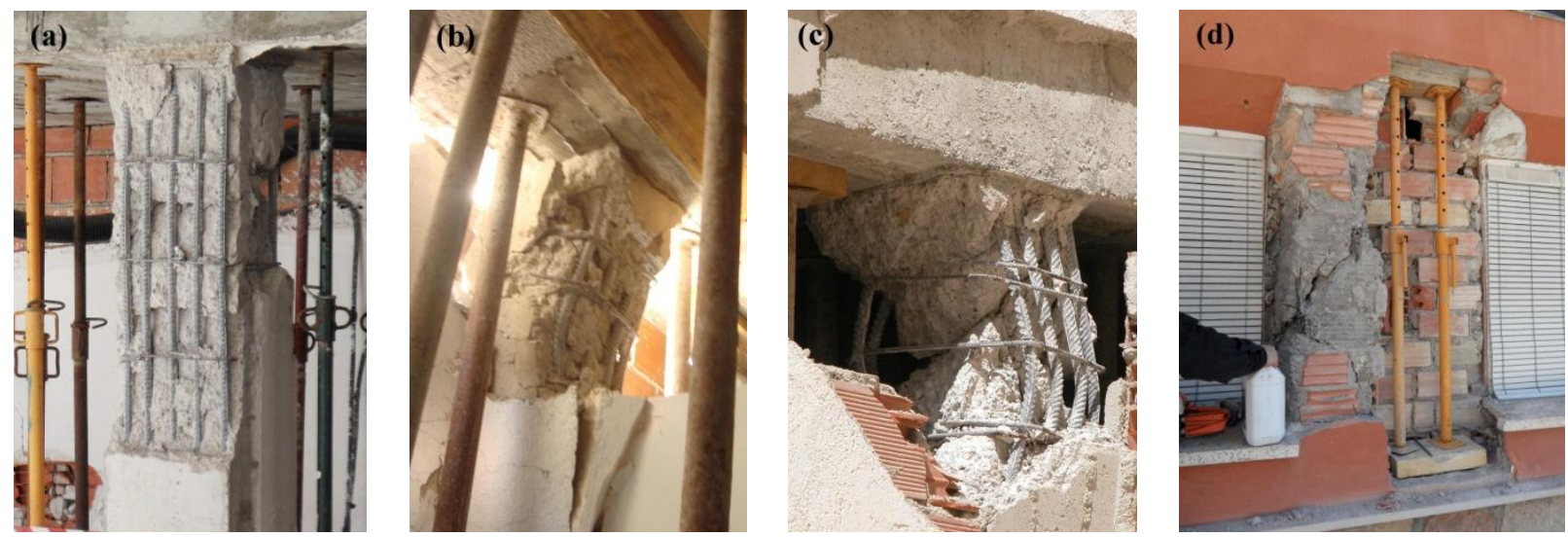

Figure 8. Brittle failures in RC columns. Photographs (b) and (c) adapted from Calconsa XXI (2011).

Beam-column joint failures were less frequent than expected (Figure 9c), especially if compared to other post earthquake reconnaissance reports in the Mediterranean area (e.g., Ricci et al. 2011a). It can be justified by the absence of typical beam-column joints given the common practice of realizing wide beams and thick flat-slab frames. According to current conventional wisdom, beamless frames of columns and flat slabs ("flat slab frames") are not considered suitable for earthquake. Such buildings are often damaged only in the vertical elements supporting the flat slab and not at the connection (Fardis, 2009).

Only one building collapsed during the earthquake (Figure 10). Its structural arrangement was characterized by RC waffle-flat plates supported by columns, with squat columns in two consecutive façades (Figure 10a) that failed and led to collapse all columns of the building (Figure 10b and 10c), (Feriche et al. 2011). No relevant damage was found in the thick waffleslab (Figure 10b). 

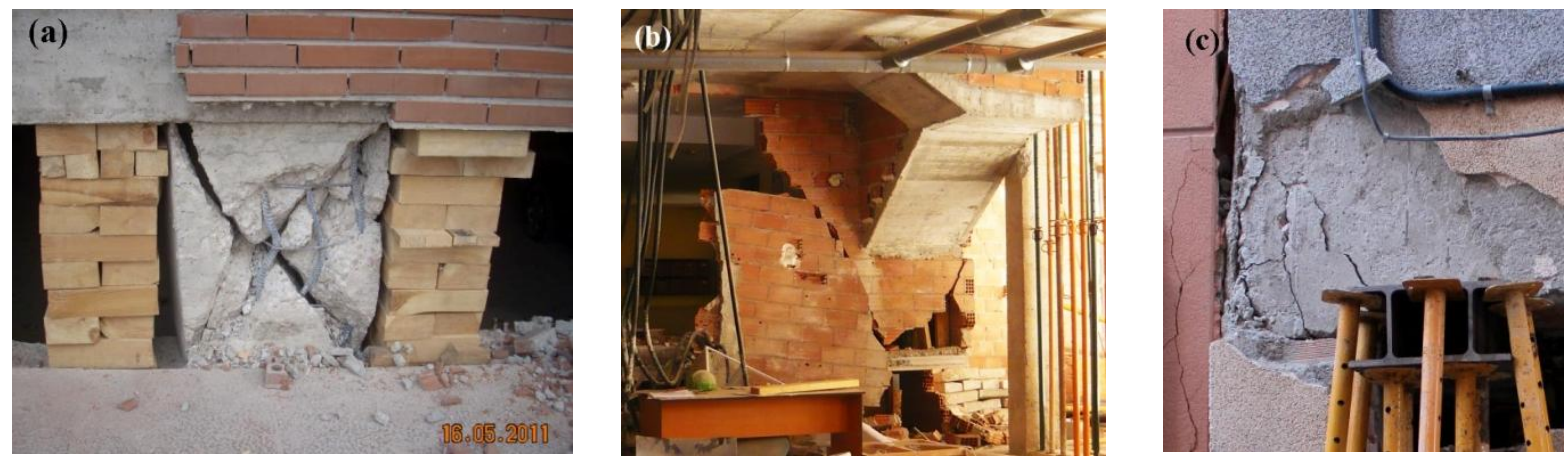

Figure 9. Brittle failure of "squat" column (a) (Vidal et al. 2011), masonry staircase (b), beam-column joint (c).
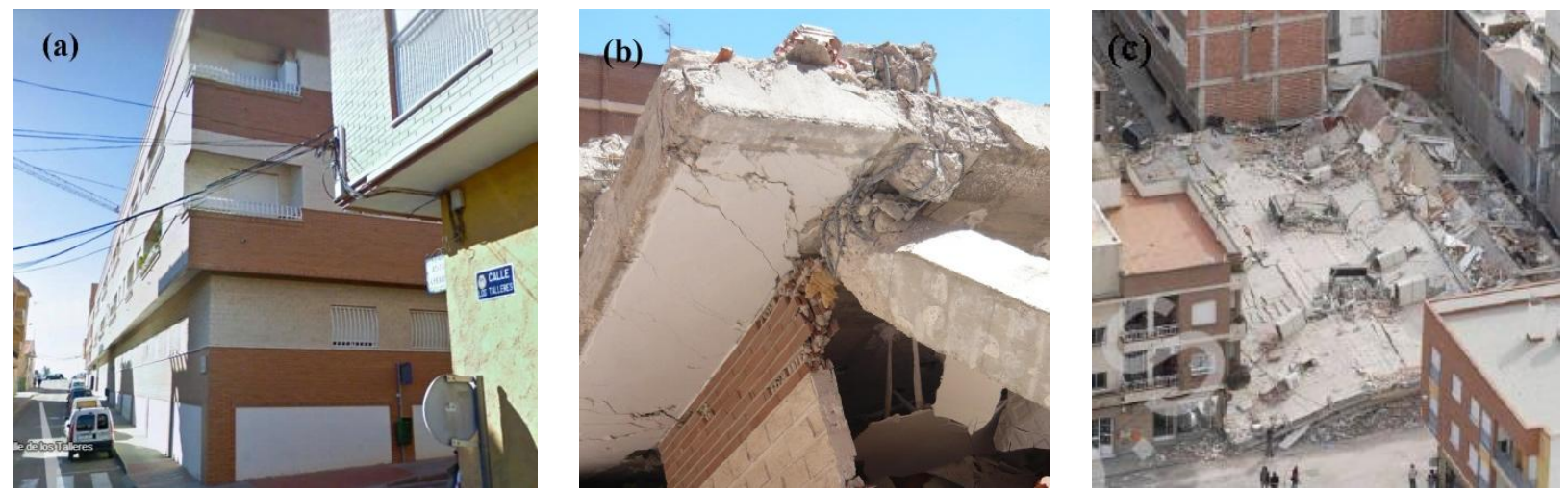

Figure 10. The only building collapsed due to the Lorca earthquake, before (Google Street View) (a) and after the event (b), (c). Photograph (c) adapted from Regalado (2011).

\subsection{Non-structural damage}

Despite most of casualties and general damage were caused by out-of-plane behavior of nonstructural elements, such as façades or balustrades, in this section, only in-plane failure of masonry infill panels of RC frames and their interaction is analyzed. The three typical in-plane failures for infill walls were recognized during in-field surveys: (i) diagonal cracking in one or two directions due to tensile stress in the central zone of the panel (Figure 11a); (ii) horizontal sliding (Figure 11b); and (iii) corner crushing in the contact zone with the surrounding frame, because of local compression stresses (Figure 11c).

Notwithstanding the fact that infill damage is nonstructural, in plane failure can lead, sometimes, to brittle failures into critical regions of RC columns because of the concentration of shear demand due to the interaction with the compressed diagonal of the panel, finally leading to undesirable progressive collapse mechanisms, (Verderame et al. 2011). 

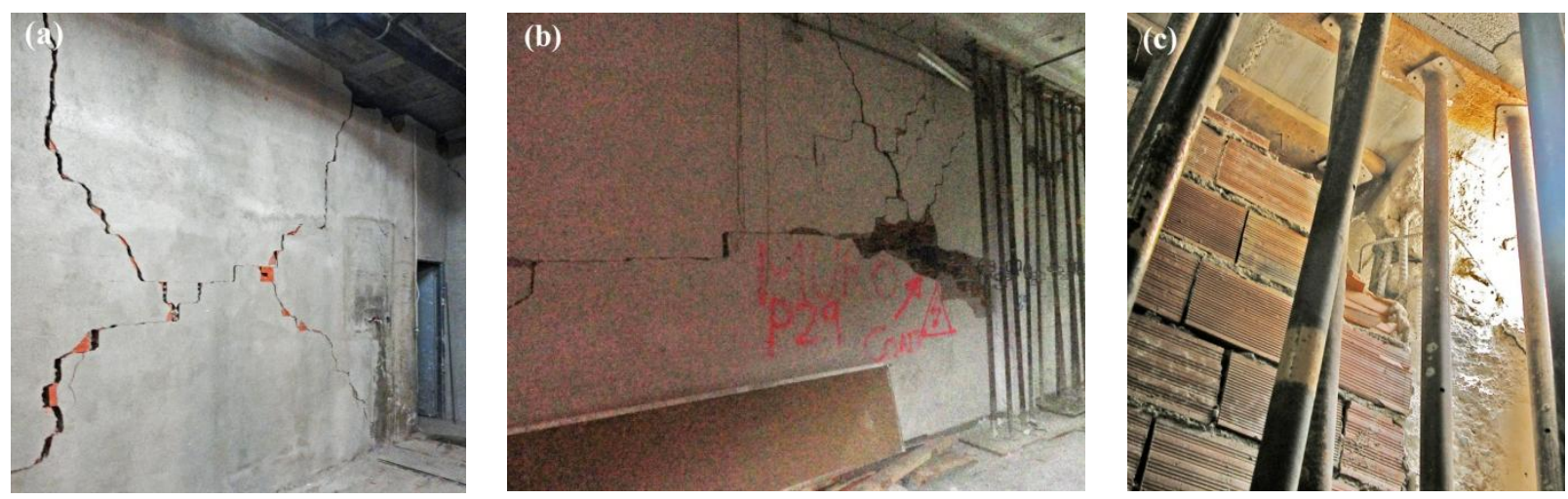

Figure 11. In-plane failures in masonry infill panels: shear diagonal cracking (a), horizontal sliding (b), corner crushing and induced brittle failure of RC column (c) (Calconsa XXI 2011).

\section{SIMPLIFIED SEISMIC PERFORMANCE ESTIMATION}

Event main characteristics and information on Lorca building stock provide, together, a likely scenario of the observed damage. On the other hand, considering directivity effects and design practice, it can be stated that damage is relatively less spread with respect to which it could have been expected. A possible explanation can be provided taking into account the structural contribution provided by masonry infills when pre-emptive brittle failures did not occurred. In the following, a simplified damage assessment procedure is developed to quantify the performance increasing provided by infills, and specialized to the characteristics of earthquake and building stock in Lorca.

\subsection{Code seismic demand}

Most of RC buildings in Lorca were designed according to PDS-1 (1974), NCSR-94 (1994) and to a lesser extent according to NCSE-02 (2002). The vast majority of them is characterized by 3 to 5 storeys, and they are designed with a behavior factor $(q)$ equal to 2 (or giving implicitly the ductility correspondent to it in the case of old code approaches, see section 3).

Design spectral acceleration at the fundamental period, other than representing code seismic demand, is the key information to establish the minimum capacity of RC building according to different codes in the case of ductile behavior (discarding the occurrence of brittle failures that cannot be considered in such simplified framework). Equations (1) and (2) show design spectra expressions provided by old and new codes, for fundamental periods higher than $T_{B}$ (the beginning abscissa of the constant acceleration branch in smoothed and code spectra). It is worth 
to note that old codes provide design spectra directly while new codes employ $q$ factor approach and provide elastic spectra that can be compared to elastic EC8 spectra $^{\ddagger}$ (Figure 12).

$S_{a}(T)=C(T) \cdot g \cdot R \cdot \delta \cdot \beta(T)$

$S_{a}(T)=a_{c} \cdot \alpha(T) \cdot \beta=\left(a_{b} \cdot \rho \cdot S\right) \cdot \alpha(T) \cdot(v / \mu)$

Approximate period formulations for old and new codes are provided in Equation (3), in which the first expression is referred to old codes (PGS-1, 1968; PDS-1, 1974) while the second one is referred to new codes (NCSR-94, 1994; NCSE-02, 2002), being $H, L$ and $N$ height, length and number of storeys of the building.

$T=0.09 H / \sqrt{L}$

$T=0.09 N$

Equation (3a) has the same functional form of numerous international codes for the evaluation of the fundamental period of RC or masonry walls structures (ATC, 1978; Crowley and Pinho, 2010); while Equation (3b) has an expression very close to $T=0.10 \mathrm{~N}$, adopted by NEHRP provisions (1994) provided for RC moment resistant frames, and successively replaced by $T=\alpha H^{0.75}$.

Actual Spanish code formulation (NCSR-94, 1994; NCSE-02, 2002) leads to different values with respect to Eurocode 8 expression (CEN, 2004). Assuming $3 \mathrm{~m}$ as the interstorey height of all storeys, Equation (3b) leads to periods 25\% lower than that provided by Eurocode, up to a total building height of $40 \mathrm{~m}$. On the other hand, Equation (3b) leads to period overestimation, up to $70 \%$, if compared to the empirical formulation $(T=0.054 N)$ based on experimental data for Lorca buildings (Navarro et al. 2012). Experimental data collected in Lorca are similar to other experimental results collected in other Spanish regions (Navarro et al. 2002; Oliveira and Navarro 2010; Kobayashi et al. 1996; Enomoto et al. 2000). Nonetheless these observations are expected. In fact, empirical data are collected on masonry infilled buildings, while Eurocode 8 formulation is meant for bare structures. Hence, infills play a significant role on building stiffness, and consequently on period (Oliveira and Navarro 2010).

\footnotetext{
* In order to enable the comparison with Spanish spectra, the transformation suggested in the proposed Spanish National Annex, 3.2.1(1),(2),(3) (Alarcón et al. 2010) has been applied, aimed at switching from different values in Eurocode to the corresponding ones in Spanish codes, respectively, for return period (475 to 500) and soil type (rock to hard) for PGA definition.
} 
In Figure 12 code spectra are shown. The following values for the site of Lorca and common RC buildings were used for design or elastic acceleration spectra. For PDS-1 (1974), $C(T)$ is the spectral amplification factor, dependent on period and on MSK value of the map (VIII for Lorca), and it is equal to 0.15 in the constant branch; $g$ is the gravity acceleration; $R$ is a factor dependent on the importance of the construction and on MSK value, being equal to 0.9. $\delta$ is a "soil factor", dependent on the type of foundation (individual footings) and type of soil (B), and it is equal to 1.1. Finally, $\beta$ is a "response factor", which depends on the infills contribution to damping and on the period. For NCSR-94 and NCSE-02, $a_{b}$ is the basic PGA measured not in rock but in hard soil, equal to $0.12 \mathrm{~g}$ for Lorca; $\rho$ is the importance factor, equal to 1.0 for dwellings. $S$ is the amplification factor for soil type B, equal to 1.00 for NCSE-94 and 1.04 for NCSE-02. $\alpha(T)$ is the spectral amplification factor, dependent on the period (and also on the soil for NCSE-94), whose maximum constant value is equal to 2.20 for NCSE-94 and 2.50 for NCSE-02. $v$ is the correction factor for damping, equal to 1.0 for $5 \%$ of the critical damping. Finally $\mu$ is the behavior factor, assumed to be 2 in most of RC buildings (see Section 3).
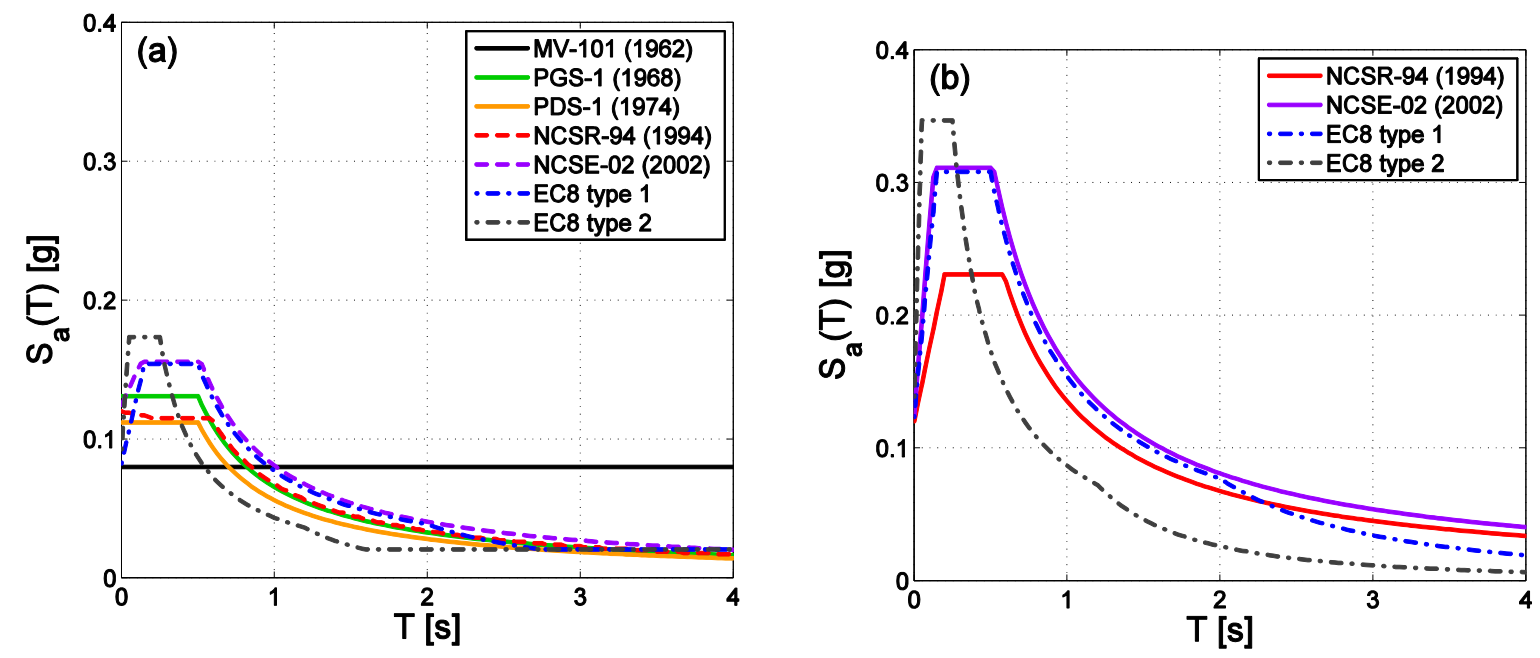

Figure 12. Design code spectra for Lorca in the case of implicit (old codes) or explicit (new codes and EC8) behavior factor q assumed equal to 2 (a); elastic code spectra for Lorca in the case of new codes and EC8 (b).

\subsection{Design based assessment}

The minimum resistant capacity of RC buildings, discarding the structural contribution of masonry infills, can be inferred as a function of the design spectral acceleration $S_{a}(T)$ employed according to the code at the age of construction, and adopting Spanish code period formulations. Referring to representative RC buildings characterizing Lorca building stock, a simplified 
capacity curve can be estimated. This approach refers to the family of spectral based methodologies (ATC-40, 1996; Kircher et al, 1997; Fajfar, 1999). It has its basis in the static pushover analysis and allows simplified code-based performance estimation by means of comparison of spectral capacity and spectral demand in the acceleration displacement format, the so called ADRS format.

The idealized pushover curve is defined by an elastic plastic backbone characterized by two characteristic points, the yielding capacity $\left(\Delta_{y}, V_{y}\right)$ and the ultimate capacity $\left(\Delta_{u}, V_{y}\right)$. The first represents the lateral strength of the building and accounts for design strength, redundancies in design, conservatism in code requirements and expected (rather than nominal) strength of materials. The ultimate displacement capacity, in this code-based approach, is computed as function of the design behavior factor $q$ and the available ductility $\mu$ that can be inferred from it.

In Figure 13a is shown an example of idealized pushover curve in which $V_{d}$ is the design base shear, $V_{l}$ is the yielding of the first element, and $V_{y}$ represents the structural yielding point (lateral strength). Aimed at switching from $V_{d}$ to $V_{y}$, two overstrength factors have to be considered: $R_{\omega}$ accounting for material overstrength, so that $V_{1}=V_{d} \cdot R_{\omega}$, and $R_{\alpha}$, accounting for structural redundancies and elements overstrength with respect to design values, so that $V_{y}=V_{1} \cdot R_{\alpha}$ (Borzi and Elnashai, 2000). The idealized pushover curve defined above, in the force displacement format, can be converted in a equivalent single degree of freedom (SDOF) capacity curve in the ADRS format; finally leading to spectral design-based assessment. In Figure $13 \mathrm{~b}$ a simplified scheme of the SDOF capacity curve in the ADRS format is provided. This approach is very close to other vulnerability based methodologies available in literature (e.g., Kircher et al, 1997).

The definition of $C_{s}$, the inelastic spectral acceleration attained at the plateau of the capacity curve, is shown in Equation (4), being $M$ the mass employed for the evaluation of the design base shear (in the lateral force method it is generally an approximate evaluation of the participating mass of the first mode by means of a reducing coefficient $), \Gamma_{1}$ the first mode participation factor, and $m_{1}$ the mass of the equivalent SDOF (the generalized mass corresponding to the first vibration mode). Once $C_{s}$ is defined, the yielding spectral displacement $\left(S_{d, y}\right)$ in the ADRS format is defined through the fundamental mode period of the structure $T$, see Equations (3), while the

\footnotetext{
${ }^{\S}$ In Eurocode 8 (CEN, 2004) such an approximate evaluation is made through a factor $\lambda$, equal to 1 in the case of building with less than three storeys and 0.85 otherwise.
} 
ultimate displacement capacity $\left(C_{d}\right)$ is defined through the ductility $(\mu)$, as shown in Equation (5) and (6). The ductility can be defined through a $R_{\mu}-\mu-T$ relationship, in which $R_{\mu}$ is the strength reduction factor. Through $R_{\mu}$, the elastic spectral acceleration capacity can be defined, $S_{a}^{C}(T)$, as shown in Equation (7). $S_{a}^{C}(T)$ allows the definition of the IN2 curve (Dolšek and Fajfar, 2004) referred to bare frame structures.
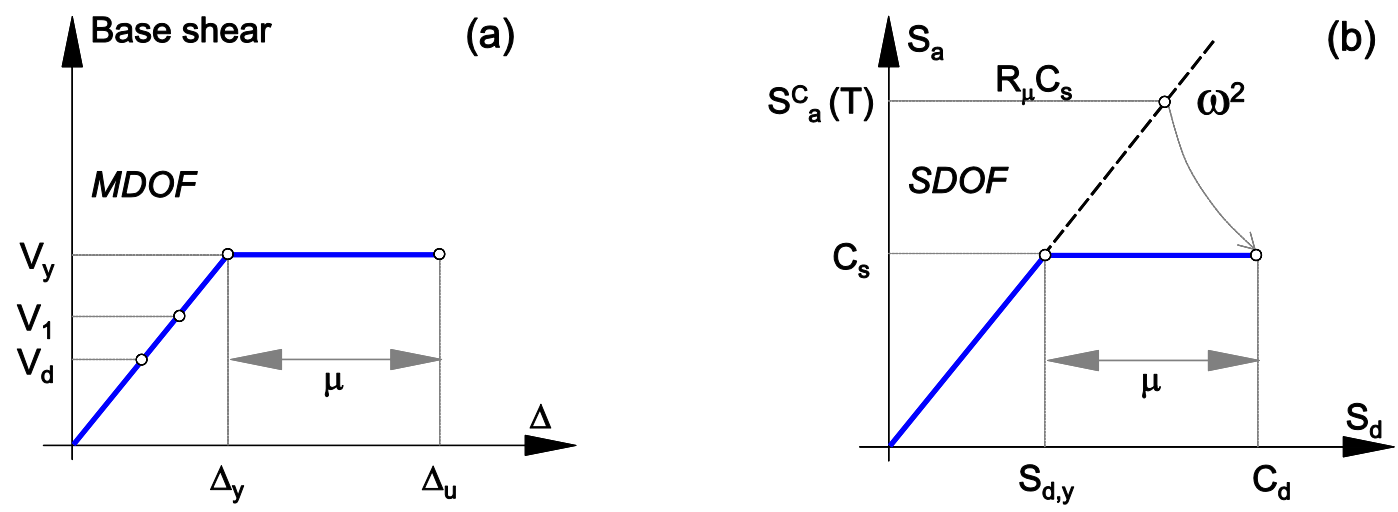

Figure 13. Example of building idealized pushover curve (a) and its representation in the ADRS format (b)

$$
\begin{aligned}
& C_{s}=\frac{V_{y}}{\Gamma_{1} m_{1}}=\frac{V_{d} \cdot R_{\alpha} \cdot R_{\omega}}{\Gamma_{1} m_{1}}=\frac{\left(S_{a}(T) \cdot M\right) \cdot R_{\alpha} \cdot R_{\omega}}{\Gamma_{1} m_{1}}=S_{a}(T) \cdot R_{\alpha} \cdot R_{\omega}\left(\frac{M}{\Gamma_{1} m_{1}}\right) \\
& S_{d, y}=C_{s} \cdot\left(\frac{T}{2 \pi}\right)^{2} \\
& C_{d}=\mu \cdot C_{s} \cdot\left(\frac{T}{2 \pi}\right)^{2} \\
& S_{a}^{C}(T)=C_{s} \cdot R_{\mu}=S_{a}(T) \cdot R_{\alpha} \cdot R_{\omega} \cdot R_{\mu}\left(\frac{M}{\Gamma_{1} m_{1}}\right)=S_{a}(T) \cdot q \cdot R_{\omega}\left(\frac{M}{\Gamma_{1} m_{1}}\right)
\end{aligned}
$$

In the following, the code-based assessment is made according the subsequent assumptions. The $R_{\mu}-\mu-T$ relationship is that by Vidic et al. (1994), also employed in Eurocode 8. Referring to Lorca building stock, and Spanish common design practice (e.g., Vielma et al, 2010), a behavior factor $(q)$ equal to 2 was assumed; $R_{\omega}$ is equal to 1.45 , in analogy with the hypothesis made in Borzi and Elnashai (2000) and similar to the ratio between medium and design yielding strength characterizing typical reinforcement steel (Galasso et al. 2010; Galasso et al., 2013). Two 
additional conservative hypotheses have been considered: $M /\left(\Gamma_{1} m_{1}\right)=1.00$, see Equation (4), with $M$ assumed as the participating mass to the first mode, and $R_{\alpha}=1.0$. The assumption on $R_{\alpha}$ is consistent with the attainment of a soft storey plastic mechanism (e.g., ground level) of the structure, in analogy with numerical findings available in literature for old seismic design structures in Spain (e.g., Benavent-Climent et al., 2004).

The strength reduction factor $R_{\mu}$ can be defined as the ratio between the behavior factor $q\left(=R_{\mu} \cdot R_{\alpha}\right)$ and the structural overstrength $R_{\alpha}$. In Table 2, results for Lorca building stock are provided for 3 and 5 storey buildings designed according to PDS-1 (1974), NCSR-94(1994), and NCSE-02 (2002). The behavior factor is equal to 2 according to Spanish code provisions and close to the value suggested in EC8 part 3 (CEN 2005) for existing buildings. Given the hypothesis made on $R_{\alpha}$, the strength reduction factor $R_{\mu}$, in this case, is equal to 2 .

Table 2. Simplified capacity estimation for 3 and 5 storeys bare RC frames.

\begin{tabular}{|c|c|c|c|c|c|c|c|c|c|c|c|c|}
\hline Number of storeys & \multicolumn{6}{|c|}{3} & \multicolumn{6}{|c|}{5} \\
\hline Heigth, $H[\mathrm{~m}]$ & \multicolumn{6}{|c|}{9.5} & \multicolumn{6}{|c|}{15.5} \\
\hline & $T$ & $S_{a}(T)$ & $C_{s}$ & $C_{d, F N}$ & $C_{d, F P}$ & $S_{a}^{C}(T)$ & $T$ & $S_{a}(T)$ & $C_{s}$ & $C_{d, F N}$ & $C_{d, F P}$ & $S_{a}^{C}(T)$ \\
\hline & {$[\mathrm{s}]$} & {$[\mathrm{g}]$} & {$[\mathrm{g}]$} & {$[\mathrm{cm}]$} & {$[\mathrm{cm}]$} & [g] & {$[\mathrm{s}]$} & {$[\mathrm{g}]$} & {$[\mathrm{g}]$} & {$[\mathrm{cm}]$} & {$[\mathrm{cm}]$} & [g] \\
\hline PDS-1 (1974) & $0.27^{(1)}$ & 0.11 & 0.16 & 0.78 & 0.59 & 0.32 & 0.44 & 0.11 & 0.16 & 1.58 & 1.57 & 0.32 \\
\hline NCSR-94 (1994) & 0.27 & 0.13 & 0.19 & 0.92 & 0.69 & 0.38 & 0.45 & 0.13 & 0.19 & 1.93 & 1.93 & 0.38 \\
\hline NCSE-02 (2002) & 0.27 & 0.16 & 0.23 & 1.08 & 0.82 & 0.45 & 0.45 & 0.16 & 0.23 & 2.27 & 2.27 & 0.45 \\
\hline
\end{tabular}

${ }^{(1)}$ The length of the building (L) employed for the evaluation of the period is equal to $10 \mathrm{~m}$.

It is worth to note that $R_{\mu}-\mu-T$ relationship provided by Vidic (1994) depends on $T_{C}$; the corner period at the end of constant acceleration branch in smoothed and code spectra. Hence, for the capacity estimation in Table $2, C_{d}$ (or equivalently $\mu$ ) can be different if considering $\mathrm{FN}$ or FP components $\left(T<T_{C}\right)$.

The total height of the buildings was assumed considering an interstorey height equal to $3.0 \mathrm{~m}$ for all the levels, $\left(h_{i n t}\right)$, with the exception of the first $\left(h_{1, i n t}\right)$ in which it was considered equal to 3.5m, according to Lorca local regulation (http://www.urbanismo.lorca.es/TomoII.asp), and in field observations made by the authors.

Once the capacity, both in term of elastic spectral acceleration and inelastic displacement, has been evaluated, it is necessary to compute the seismic demand of the event. In Table 3 elastic spectral acceleration demands $S_{a}^{D}(T)$ are shown for FN and FP mainshock signals registered at 
Lorca station. A graphical example of the procedure is shown in Figure 14 for the case of PDS-1 code for a 3 storey bare RC buildings.

Table 3. Demand estimation for bare RC frames in the case of FN and FP mainshock signals in LOR station.

\begin{tabular}{|c|c|c|c|c|}
\hline Number of storeys & \multicolumn{2}{|c|}{3} & \multicolumn{2}{c|}{5} \\
\hline \multirow{2}{*}{ Demand } & $S_{a, F N}^{D}(T)$ & $S_{a, F P}^{D}(T)$ & $S_{a, F N}^{D}(T)$ & $S_{a, F P}^{D}(T)$ \\
\cline { 2 - 5 } & {$[\mathrm{g}]$} & {$[\mathrm{g}]$} & {$[\mathrm{g}]$} & {$[\mathrm{g}]$} \\
\hline PDS-1 (1974) & 0.81 & 0.56 & 0.95 & 0.40 \\
\hline NCSR-94 (1994) \& NCSE-02 (2002) & 0.82 & 0.55 & 0.94 & 0.39 \\
\hline
\end{tabular}

The comparison of the elastic spectral acceleration demand $S_{a}^{D}(T)$ for the FN and FP components with the elastic spectral acceleration capacity $S_{a}^{C}(T)$, evaluated in Table 2 and 3, suggests a negative response of the code based assessment in most of the cases considered. The only exception is represented by FP signal demand in the case of five storeys buildings designed according to NCSE-02 (2002) code.

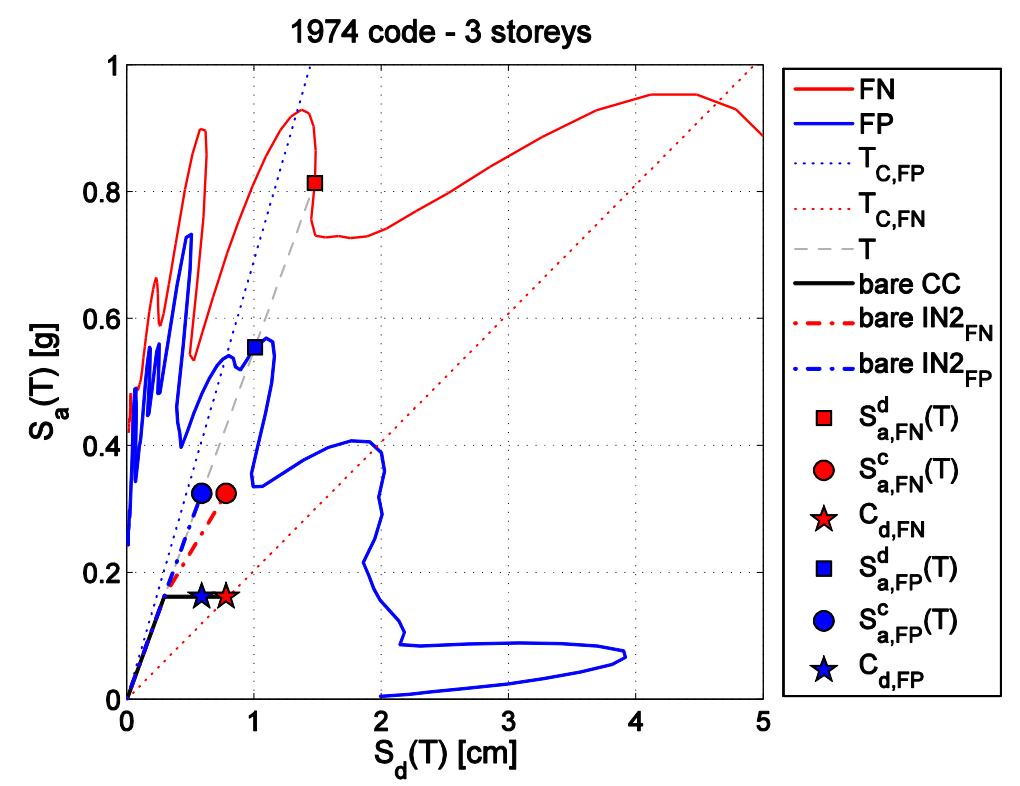

Figure 14. Simplified performance estimation of 3 storey bare RC buildings designed according to PDS-1 (1974) code.

Notwithstanding the indicative significance of the results provided; it should be observed that this code-based seismic assessment cannot be compared with in situ damage observation for two main reasons. The first reason is the conventional characteristic of the assessment performed, caused by the evaluation of the available ductility $(\mu)$ on the basis of the design behavior factor. Such an approach can be very conservative even when a first-storey plastic mechanism occurs, in agreement with the hypothesis made above. In fact, considering the ultimate SDOF displacement 
capacities $\left(C_{d}\right)$ provided in Table 2, they corresponds to drift capacities that are significantly lower than the typical ultimate capacity (e.g., 3\%) evaluated for substandard buildings (e.g. CEN, 2005). The second reason is that a code-based assessment cannot account for masonry infill structural contribution. Infill contribution to seismic performances can strictly characterize the first three levels of damage according to EMS98 scale, that are also the most frequent observed damage levels resulting from field surveys (see Figure 7).

\subsection{Damage assessment of infilled RC MRF structures: FAST vulnerability approach}

The approximate estimation of the capacity curve for reinforced concrete moment resisting frame (RC MRF) structures can be also carried out in the case of infilled structures; thus accounting for the structural contribution provided by infills. Furthermore, for infilled RC MRF structures, it is possible to pursue, rather than a simple code-based assessment, FAST damage assessment procedure that allows a preliminary comparison with damage observed data, thanks to (i) a simplified definition of the capacity curve of a RC infilled building and (ii) an approximate mechanical interpretation of damage states according to EMS98 scale.

It is well known that infills structural contribution, on one hand, provides an increasing of the strength and of the lateral stiffness of the building (resulting in a decreasing of the fundamental period); on the other hand, they lead to global strength degradation up to a minimum value, given their brittle nature (see Figure 15a). The structural behavior described above is mainly representative of substandard existing buildings uniformly infilled (Dolšek and Fajfar 2001). It is worth to note that structural effects caused by irregular distribution of infills are not accounted for in this simplified vulnerability approach.

Hence the simplified capacity curve of a uniformly infilled RC MRF building can be represented by a quadrilinear backbone (Dolšek and Fajfar, 2005) characterized by an initial elastic plastic backbone (with a maximum base shear strength equal to $V_{\max }$ ), followed by a softening branch up to ae minimum base shear strength $\left(V_{\min }\right)$. Even if more accurate piecewise linear approximations of the capacity curve are available in literature (De Luca et al., 2013), Dolšek and Fajfar's approach is thought for the $R_{\mu}-\mu-T$ that is going to be employed, so it is well suited for the framework of this study. In this simplified definition of the capacity curve the softening branch is characterized by a drop. The latter is an additional simplifying hypothesis 
with respect to the idealized backbone provided by Dolšek and Fajfar (2005), and refers to a significant brittle behavior of the infills.

Figure 15 show a qualitative example of the approach leading to the definition of the capacity curve in ADRS format. In Figure 15a, the typical shape of a pushover curve on infilled RC structures is shown with a qualitative example of the contribution provided by infills and RC frames. The idealized capacity curve is shown in Figure $15 \mathrm{~b}$ and $15 \mathrm{c}$, respectively in base shear displacement format $(V-\Delta)$ and ADRS format $\left(S_{a}-S_{d}\right)$.
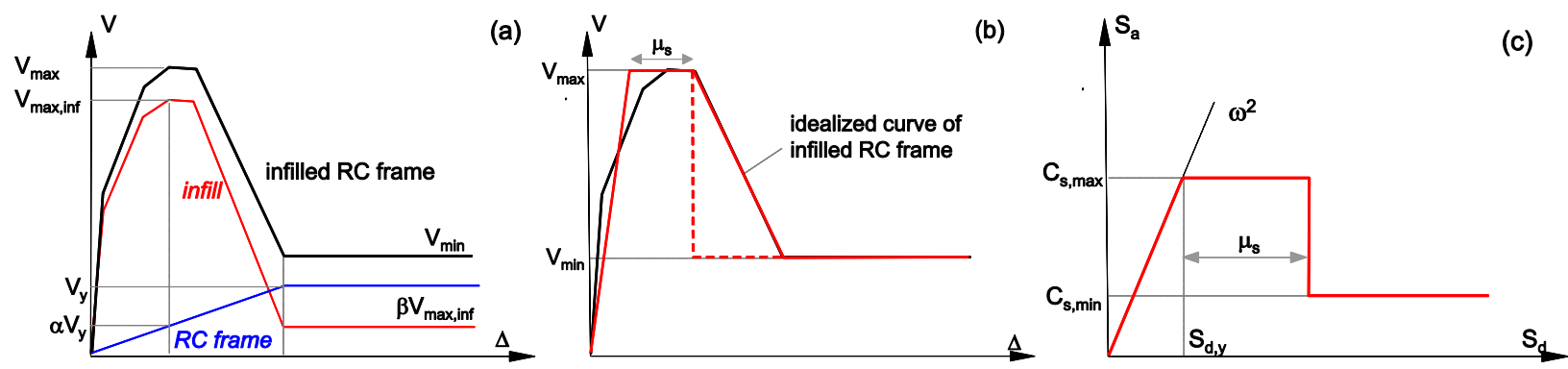

Figure 15. Example of infilled RC frame pushover curve (a), its quadrilinear idealization in the base shear displacement format (b), and ADRS format (c).

\subsubsection{Simplified capacity curve of infilled RC MRF structures}

According to the representation in Figure 15c, the simplified capacity curve in ADRS format can be defined through the definition of four parameters:

- $C_{s, \max }$, the inelastic acceleration of the equivalent SDOF at the attainment of the maximum strength $V_{\max }$;

- $\quad C_{s, \min }$, the inelastic acceleration of the equivalent SDOF at the attainment of the plastic mechanism of the RC structure (at which all the infills of the storey involved in the mechanism have attained their residual strength $\left.\beta V_{\text {max,inf }}\right)$;

- $\quad \mu_{s}$, the available ductility up to the beginning of the degradation of the infills.

- $\quad T$, the equivalent elastic period computed from the fundamental period $T_{o}$ of the infilled RC buildings.

In Equations (8) and (9) are shown the formulations assumed for the definition of the first two parameters, while the value of $\mu_{s}$ was assumed equal to 2.5. The latter assumption was made through a comparison on detailed assessment studies available in literature on gravity load 
designed buildings (Ricci et al., 2011b; Verderame et al., 2012, Verderame et al., 2013; Manfredi et al, 2013) to which Spanish old seismic designed buildings can be considered to be similar (Benavent-Climent et al., 2004).

$$
\begin{aligned}
& C_{s, \text { max }}=\frac{V_{\text {max }}}{\Gamma_{1} m_{1}}=\frac{V_{\text {max, inf }}+\alpha V_{y}}{\Gamma_{1} m_{1}}=\frac{\alpha V_{y}+\tau_{\max } \cdot A_{\mathrm{inf}}}{\Gamma_{1} m_{1}}=\alpha C_{s}+\frac{\tau_{\max } \cdot \rho_{\mathrm{inf}} \cdot A_{b}}{\left(N \cdot m \cdot A_{b} \cdot \lambda\right)}=\alpha C_{s}+\frac{\tau_{\max } \cdot \rho_{\mathrm{inf}}}{N \cdot m \cdot \lambda} \\
& C_{s, \text { min }}=\frac{V_{y}+\beta V_{\text {max, inf }}}{\Gamma_{1} m_{1}}=C_{s}+\beta \frac{\tau_{\max } \cdot \rho_{\mathrm{inf}}}{N \cdot m \cdot \lambda}
\end{aligned}
$$

where:

$V_{\text {max,inf }}$ is the maximum base shear provided by the infills;

$\tau_{\max }$ is the maximum shear stress of the infills;

$\rho_{\text {inf }}$ is the ratio between the infill area (evaluated along one of the principal directions of the building) and the building area $A_{b}$;

$N \quad$ is the number of storeys;

$m$ is the average mass of each storey normalized by the building area (e.g. equal to $0.8 \mathrm{t} / \mathrm{m}^{2}$ for residential buildings);

$\lambda \quad$ is a coefficient for the evaluation of the first mode participant mass respect to the total mass of the MDOF (CEN, 2004), equal to 0.85 for buildings with more than three storeys; $\alpha, \beta$ coefficients that account, respectively, for the RC elements' contribution at the attainment of $V_{\max , i n f}$ and for the residual strength contribution of the infills at the attainment of the plastic mechanism of the RC structure, see Figure 15a.

Equations (8) and (9) are evaluated in the hypothesis of the attainment of a soft storey plastic mechanism (e.g., ground level) of the structures. In fact, in the case of substandard existing buildings (without any capacity design), storey strength and stiffness of the RC structure has a negligible influence if compared to the contribution of the infills (Dolce et al., 2005; Ricci et al., 2011b). In particular, for uniformly infilled RC buildings, storey strength and stiffness is approximately constant along the height of the building. Thus, considering the typical inverted triangular distribution of lateral force method (first mode distribution), damage is concentrated at the first storey (given its higher storey shear). The subsequent drop in strength, caused by brittle 
nature of infills, finally leads to a soft storey ductile mechanism governed by RC columns at ground level (Dolce et al., 2005).

The last parameter to be evaluated for the definition of the capacity curve is the equivalent elastic period $T$. In analogy with the original approach by Dolšek and Fajfar (2005), the equivalent elastic period can be computed according to Equation (10); in which the displacement $S_{d, y}$ (see Figure 15c) can be obtained by a piecewise linear approximation of the capacity curve. The first branch of the curve represents both the initial elastic and the post-cracking behavior occurred in both the RC frame and the infill; hence, the equivalent elastic period $T$, in the idealized capacity curve, is higher than the fundamental elastic period $T_{0}$, correspondent to the tangent stiffness at the beginning of the capacity curve. In particular, in this study, $T$ is evaluated from a relationship with $T_{0}$, through a coefficient $\kappa$.

$$
T=2 \pi \sqrt{\frac{S_{d, y}}{C_{s, \max }}}
$$

The fundamental period $T_{0}$ of an infilled RC MRF can be obtained from the formulations available in literature, whose functional form is $T=\alpha N$, carried out form regressions on experimental data obtained by means of techniques based on low amplitude motion, as microtremors or ambient noise. Several of these studies were carried out on infilled RC buildings in Mediterranean area. Moreover, due to the nature of the applied measurement techniques, it is likely to assume that these relationships provide a value of the period, corresponding to a linear behaviour of structural materials and components. Period-height relationships reported in studies concerning Spanish and Portuguese buildings (Kobayashi et al., 1996; Enomoto et al. 2000, Navarro et al. 2002, Oliveira, 2004; Navarro and Oliveira, 2004, Oliveira and Navarro, 2010), are considered. All the studies mentioned above lead to period formulation ranging in the interval in Equation (11).

$$
T_{o}=(0.045 \div 0.054) N
$$

Notwithstanding the fact that Oliveira and Navarro (2010) emphasized how experimental and numerical data are quite different, the numerical study provided in Ricci et al. (2011c) shows a very good agreement with the same data, justified by the different stiffness model proposed for the infills in the analytical investigations. Ricci et al. (2011c) provided different formulations, see 
Equation (12). $A_{i n f}$ is the ratio (in percentage) between the infill area along the considered direction and the building area.

$T_{o}=0.049 \mathrm{~N}$

$T_{o}=0.016 H$

$T_{o}=0.023 \frac{H}{\sqrt{A_{\mathrm{inf}}}}=0.023 \frac{H}{\sqrt{100 \rho_{\mathrm{inf}}}}=0.0023 \frac{H}{\sqrt{\rho_{\mathrm{inf}}}}$

Equation (12a) confirms the very good agreement with Equation (11). Equation (12b) is obtained from Equation (12a) considering a constant interstorey height equal to 3m; while Equation (12c) is characterized by a closer agreement with numerical data (Ricci et al. 2011c).

In FAST, Equation (12c) is employed, given its good agreement with experimental data and the presence of variables already employed in the evaluation of the simplified capacity curve, see Equations (8) and (9). Finally the switch from $T_{0}$ to the equivalent elastic period $T$ is made through the amplification coefficient $\kappa$, calibrated on detailed analytical data (Verderame et al., 2012; Verderame et al., 2013, Manfredi et al., 2013), and assumed equal to 1.4.

For the evaluation of the capacity curves in Figure 16 the subsequent assumptions have been considered. $\alpha$ and $\beta$ coefficient have been considered equal to 0.5 and 0 , respectively. The value of $\tau_{\max }$ was chosen equal to $1.3 \cdot \tau_{c r}$, according to Fardis (1997) and assuming $0.35 \mathrm{MPa}$ for $\tau_{c r}$, the latter according to the average value suggested by Italian code provisions for hollow bricks (CS. LL.PP. 2009). Finally $\rho_{\text {inf }}$ was chosen equal to 0.025 in analogy with data available in (Ricci et al., 2011b; Crowley and Pinho, 2010).

The definition of an infilled capacity curve allows, in turn, the definition of the IN2 curve according to Dolšek and Fajfar' s (2004) $R_{\mu}-\mu-T$ relationship for infilled RC structures. The hypothesis made on the drop of the capacity curve does not affect the evaluation of the corresponding IN2, since this parameter was considered not significant in the regression, and it is not included in the $R_{\mu}-\mu-T$.

It is worth to note that the $R_{\mu}-\mu-T$ relationship for infilled RC structures asks for both $T_{C}$ and $T_{D}$ for its employment. $T_{D}$ defines the beginning of the constant displacement response range of the spectra. $T_{C}$ and $T_{D}$ assume different values in the case of the FN and FP spectra as shown 
in section 2. Spectral differences between the two signals justify the differences between the IN2 curves for FN and FP cases shown in Figure 16.
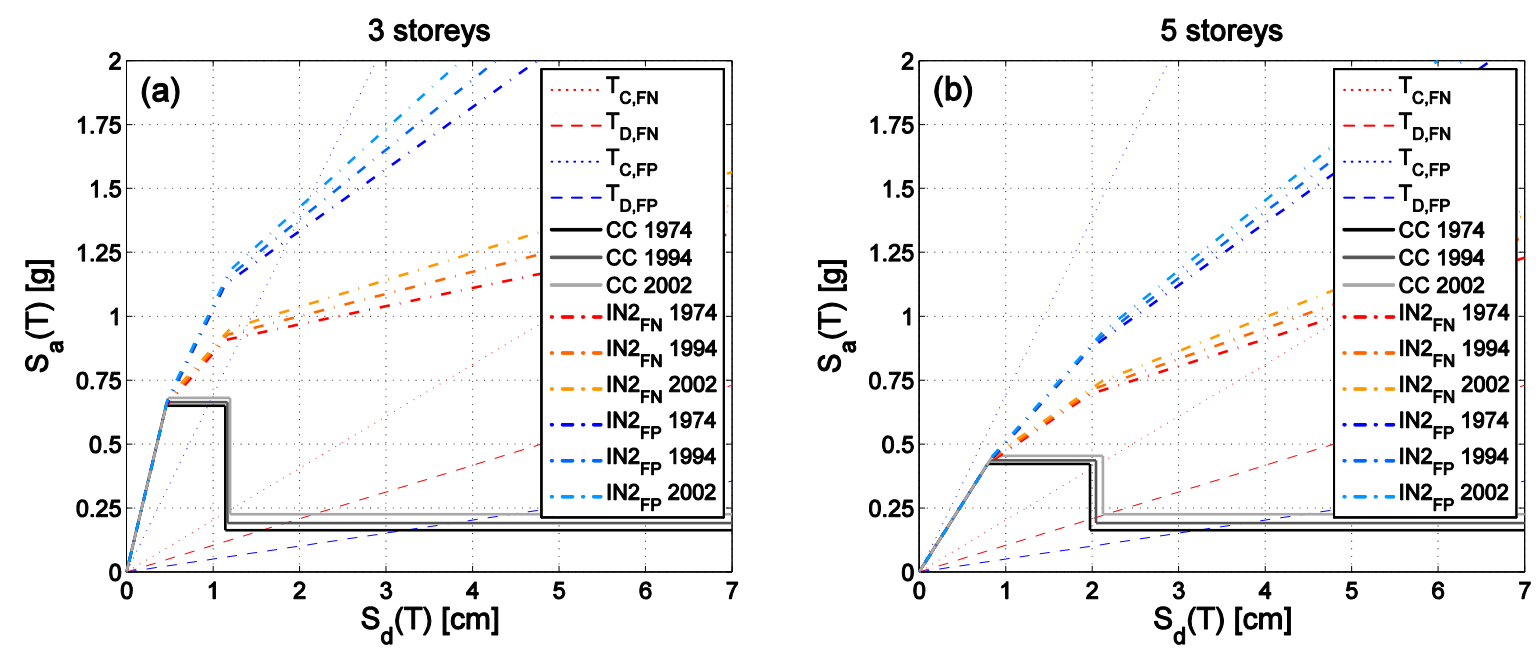

Figure 16. Approximate capacity curves (CC) and IN2 curves for 3 (a) and 5 storeys (b).

\subsubsection{Infilled damage states}

The empirical-mechanical interpretation of damage states in terms of interstorey drift (IDR), and consequently in terms of equivalent SDOF displacement, $(S d)$ can be defined according to the classification of the EMS-98 scale (Grunthal, 1998). Once such interpretation is defined the simplified approach aimed at determining the IN2 curves allows the evaluation of damage states in terms of $S a(T)$ and $P G A$.

The evaluation of the equivalent SDOF displacement, given the specified DS level ( $S_{d \mid D S_{i}}$ ) can be made as function of the storey IDR at which the DS is attained in the building. In fact, once the $I D R_{\mid D S_{i}}$ is computed, the roof displacement can be defined through a deformed shape defined a priori. The switch from roof displacement of the MDOF to $S_{d \mid D S_{i}}$ is made through $\Gamma_{1}$ defined according to the ASCE/SEI 41-06 (2007), the so called $C_{0}$ coefficient. The IN2 curve in terms of $S a(T)$ allows the definition of the spectral acceleration for each damage state $\left(S a(T)_{\mid D S_{i}}\right)$. Finally, scaling of $S a(T)_{\mid D S_{i}}$ to $P G A_{\mid D S_{i}}$, according to the spectral shape considered, completes the procedure. 
In this study, the definition of $I D R_{\mid D S_{i}}$, according to EMS98 is made for the only damage states characterized by a specific infill damage level. In particular such procedure can be pursued up to DS3:

- DS1: Fine cracks in partitions and infills. This DS is defined by the end of the phase in which infills are characterized by an elastic, uncracked stiffness. The $I D R_{\mid D S 1}$ could be evaluated as the drift characterizing the attainment of the cracking shear in the infill backbone (Fardis, 1997). Notwithstanding the value of a pure mechanical approach, in this approximate framework the $I D R$ of the first storey at the specific damage level has been defined on experimental basis (Colangelo, 2012). Thus the $I D R_{\mid D S 1}$ for the first storey is assumed equal to 0.0003 . It is worth to note that such experimental value is similar to that computed on pure mechanical basis assuming typical infill characteristics of residential buildings (e.g., clay hollow bricks).

- DS2: Cracks in partition and infill walls, fall of brittle cladding and plaster. Crack pattern of the infill is typical of their theoretical post-cracking behavior up to the attainment of the peak strength. In a pure mechanical approach, $I D R_{\mid D S 2}$ could be evaluated as the drift corresponding to the peak of the backbone according to Fardis' model (1997). The stiffness at this point can be computed according to the secant formulation by Mainstone (1970). On the other hand, in this case, again, the experimental basis for the evaluation of the IDR of the first storey was preferred and the value assumed is equal to 0.002 (Dolšek and Fajfar, 2008; Colangelo, 2012).

- DS3: Large cracks in partition and infill walls, failure of individual infill panels. At this stage the generic infill panel shows a significant strength drop with a consequent likely collapse of it. According to Fardis' backbone, the drift at this stage is strictly dependant on the softening stiffness of the infill. On the other hand the softening stiffness is characterized by a large variability depending on the specific infill (mechanical properties, type of bricks,...). In such situation the experimental basis is the most reliable solution (Colangelo, 2012). Furthermore, it is worth to note that experimental data by Colangelo refer to the typical infills employed in residential buildings of the Mediterranean area. Hence, in this case $I D R_{\mid D S 3}$ is assumed equal to 0.012 . 
Once the characteristic $I D R_{\mid D S_{i}}$ are defined, the definition of $S_{d \mid D S_{i}}$ can be computed through a deformed shape defined a priori. In particular, the deformed shape at a given DS level is evaluated according the two following assumptions: (i) the $I D R_{\mid D S_{i}}$ is attained at the first storey; (ii) the deformed shape of the $N-1$ storeys is evaluated as function of their stiffness and that expected at the first storey.

In the case of DS1 and DS2, $S_{d \mid D S_{i}}$ is evaluated according to Equation (13). The IDR of the $\mathrm{i}^{\text {th }}$ $(i>1)$ storey is computed considering an inverted triangular distribution of lateral forces as shown in Equation (14), in which $H_{i}$ and $H_{j}$ are the heights of the $\mathrm{i}^{\text {th }}$ and $\mathrm{j}^{\text {th }}$ storeys above the level of application of the seismic action (foundation or top of a rigid basement). The coefficient $\gamma$ in Equation (13) is the average of the ratio, $\gamma_{i}=K_{1} / K_{i}$, between the stiffness of the first storey $\left(K_{l}\right)$ and that of the $\mathrm{i}^{\text {th }}$ storey $\left(K_{i}\right)$, all evaluated considering the only infills' contribution and neglecting the concrete stiffness contribution at the different storeys.

$$
\begin{aligned}
& S_{d \mid D S}=\frac{1}{\Gamma_{1}}\left(I D R_{\mid D S} \cdot h_{1, \mathrm{int}}+\gamma \cdot \sum_{i=2}^{n} I D R_{i} \cdot h_{\mathrm{int}}\right) \\
& I D R_{i}=I D R_{\mid D S}\left(1-\sum_{1}^{i-1} \frac{H_{i}}{\sum_{j=1}^{n} H_{j}}\right)
\end{aligned}
$$

In the case of DS1 the stiffness of the all the storeys is still elastic; thus leading to $\gamma=1.0$. For DS2 a linear distribution of the stiffness along the height of the building is assumed. Thus, it is evaluated considering a secant stiffness at the first storey (Mainstone, 1970), $K_{\text {sec, Main }}$, and elastic at the top storey, $K_{e l}$. Based on numerical and experimental results (e.g. Ricci et al, 2011b; Colangelo, 2012), the secant stiffness was considered as the $25 \%$ of the elastic, leading to the evaluation of $\gamma$ as shown in Equation (15).

$$
\gamma=\frac{2 K_{\text {sec, Main }}}{\left(K_{e l}+K_{\text {sec, Main }}\right)}=\frac{2\left(0.25 K_{e l}\right)}{\left(K_{e l}+0.25 K_{e l}\right)}=0.4
$$

For DS3, $S_{d \mid D S 3}$ is evaluated assuming the same deformed shape for the $N-1$ storeys as that computed for DS2 and displacement increasing is generated by $I D R_{\mid D S 3}$, as shown in Equation (16). The latter assumption implies that the unloading stiffness of the $N-1$ storeys is infinite. 
$S_{d \mid D S 3}=S_{d \mid D S 2}+\frac{\left(I D R_{\mid D S 3}-I D R_{\mid D S 2}\right) \cdot h_{1, \text { int }}}{\Gamma_{1}}$

The definition of $S d_{\mid D S_{i}}$ for the three DS allows the consequent definition of $S a(T)_{\mid D S_{i}}$, through the IN2 curve. In fact, $S d_{\mid D S_{i}}$ is the expression of the characteristic equivalent SDOF displacement that represents the abscissa in the ADRS format in which the IN2 is computed. Thus, the IN2 curve becomes the tool by which $S a(T)_{\mid D S_{i}}$ can be defined. Given $S a(T)_{\mid D S_{i}}$, the switch to $P G A_{D S S_{i}}$ is pursued through a spectral scaling procedure. Each $S a(T)_{\mid D S_{i}}$ is divided by the ratio of the spectral acceleration demand at $T$, and the PGA demanded, $S a_{d}(T) / P G A_{d}$.

The above damage evaluation in terms of $S d_{\mid D S_{i}}, S a(T)_{\mid D S_{i}}$, and $P G A_{\mid D S_{i}}$ is now applied in the case of Lorca building stock. As an example, the three DS are evaluated in terms of $S d_{\mid D s_{i}}$ and $P G A_{D S_{i}}$ for 3 and 5 storeys buildings designed according to PDS-1 (1974) code, as shown in Figure 17 and 18, respectively. Results in terms of $P G A_{D S_{i}}$ for 3 to 6 storeys buildings designed according to the three codes considered are shown in Figure 19 and compared with the PGA demanded in the case of FN and FP signals. The different values of $T_{C}$ and $T_{D}$ between the two signals are the main cause of the differences in the IN2 curves.

Figure 19 shows an increasing trend of $P G A_{D S_{i}}$ with the increasing number of storey. This is a typical result that can be found in different large scale vulnerability approaches. Such an effect can be observed easily in the case of FN signal rather than FP. In fact, it should be observed that $P G A_{D S_{i}}$ are affected by the employment of spectra corresponding to registered waveforms characterized by a natural irregular shape. In the case of smoothed and code spectra, with the typical Newmark-Hall functional shape (e.g., CEN, 2004), the increasing trend of $P G A_{D S_{i}}$ with the increasing number of storeys would have been clearer (e.g., Verderame et al., 2012).

On the other hand, the employment of the spectra of the registered signals allows a direct comparison with observed damage shown in Figure 7. The PGA demanded $\left(\mathrm{PGA}_{d}\right)$ of the FN signal is always in the DS2 range, while $\mathrm{PGA}_{d}$ of the FP signal is in DS1 range with the exception of 5 storeys buildings, see Figure 19. Results are in good agreement with median values shown for 3 to 6 storeys in damage data (see Figure 7a); "grade 2" (or D2) is the dominant output of the damage surveys. Differences between design approaches according to the three 
different codes are negligible, see in Figure 19. On the other hand, similar results can be observed in Figure 7b, in which the design approach does not affect significantly the EMS98 damage classification.
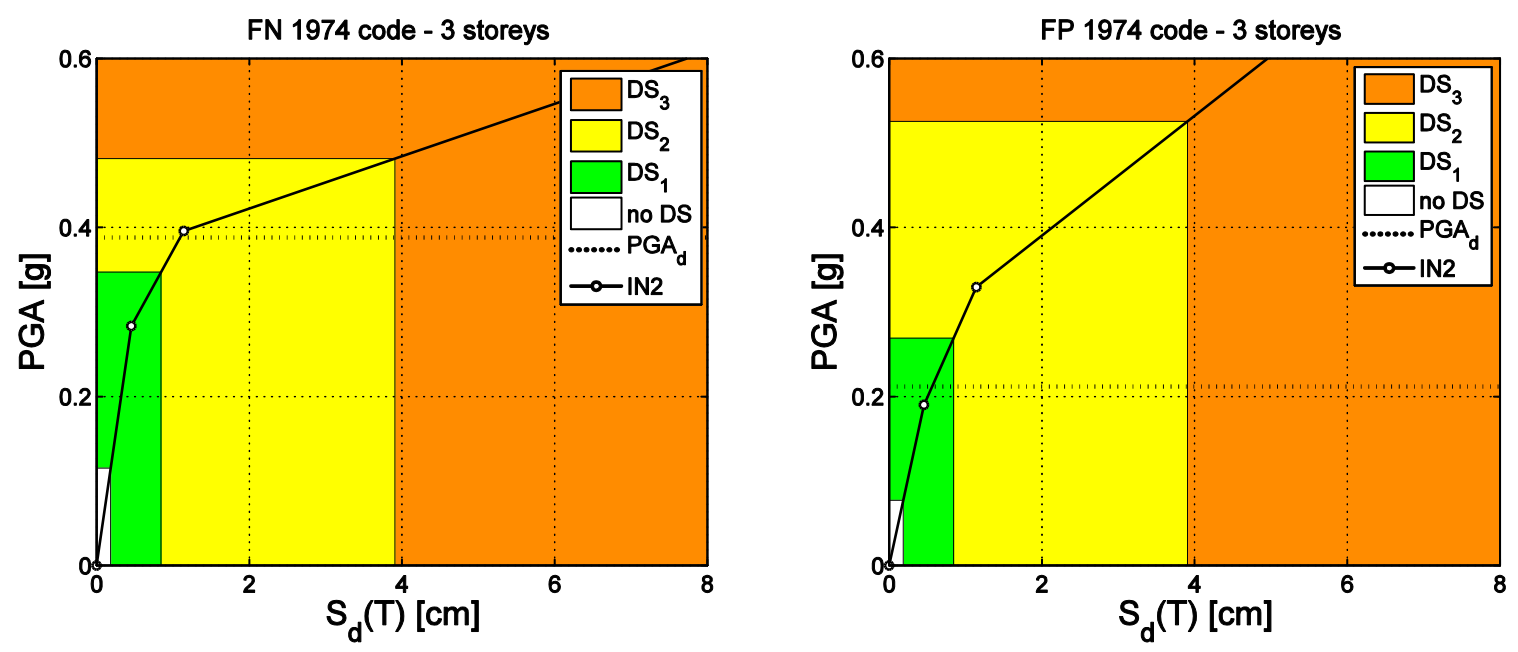

Figure 17. Damage assessment in terms of PGA for 3 storey buildings designed according toPDS-1 (1974) code in the case of FN and FP spectra.
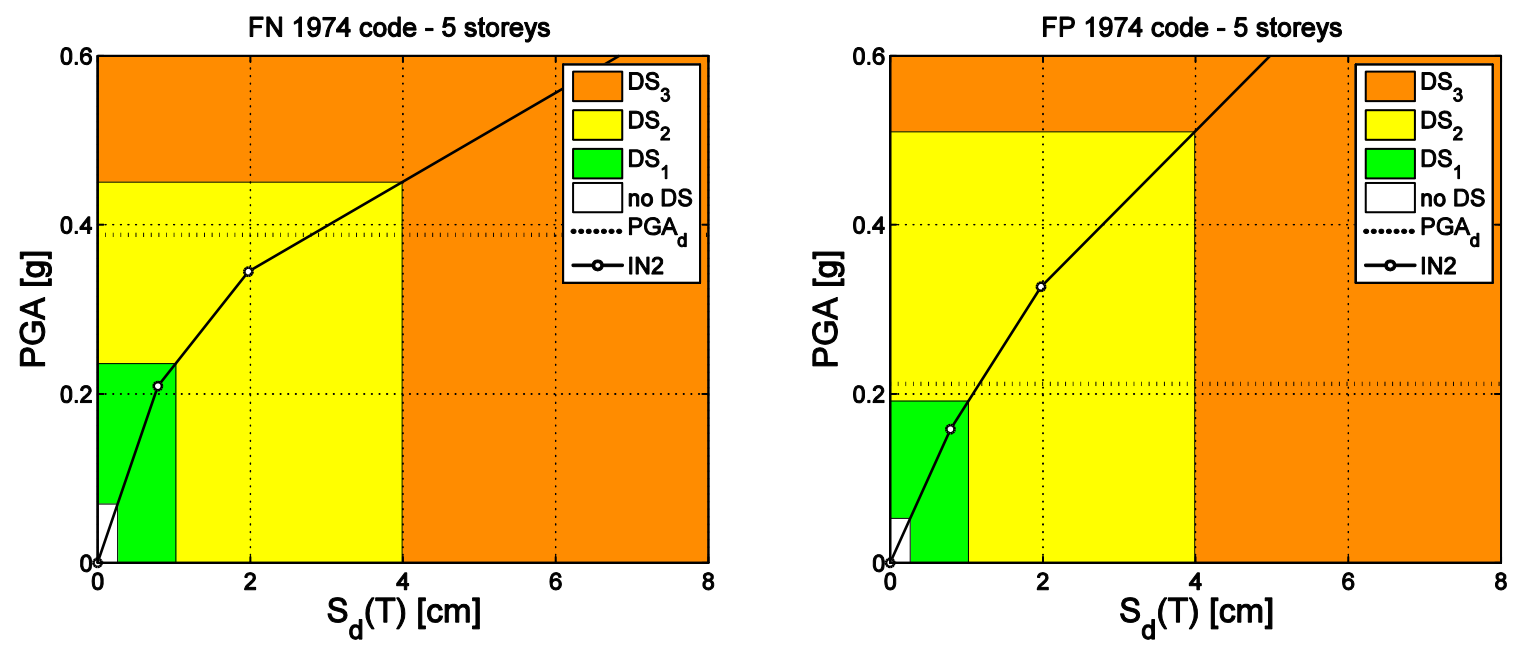

Figure 18. Damage assessment in terms of PGA for 5 storey buildings designed according toPDS-1 (1974) code in the case of FN and FP spectra.

The trend of damage data with storeys in the case of "grade 1" is very similar to that shown in the case of DS1 for the FN signal, see Figure 7a and Figure 19a. The irregular trend of "grade 2" with the storeys observed in Figure 7a; characterized by a higher number of 6 storey buildings in DS2 with respect to the number of 5 storey buildings in the same DS, is similar to the non regular trend of DS2 shown in both the case of FN and FP signals in Figure 19. 
FN

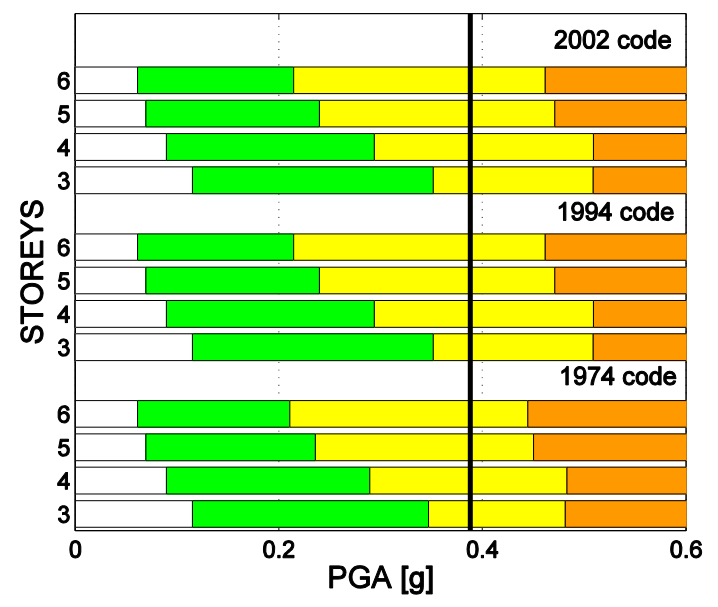

FP

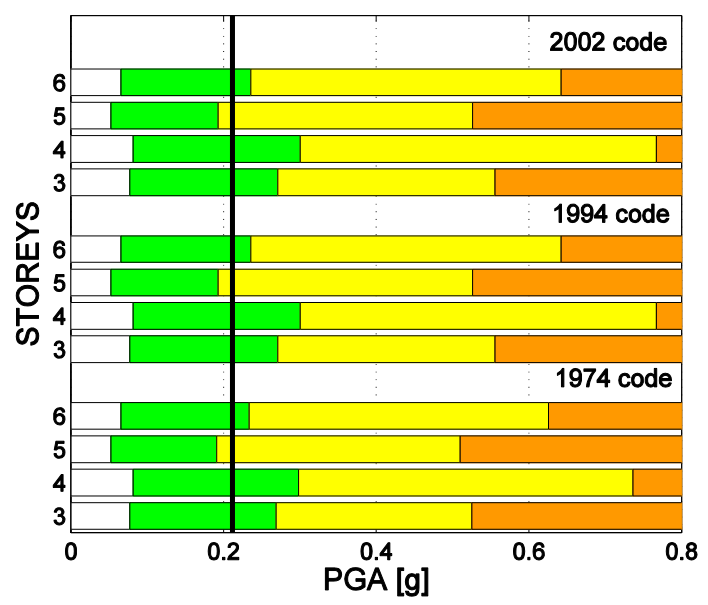

Figure 19. Damage assessment in terms of PGA in the case of FN (a) and FP (b) for the three different codes considered and 3 to 6 storeys buildings.

FAST vulnerability approach allows the only characterization of damage states that depends on infills. The procedure is not able to provide any prediction regarding "grade 4" and "grade 5" since the corresponding damage states, according to EMS-98, are fully characterized by damage on RC elements. On the other hand, most of buildings classified in "grade 4" and "grade 5", after Lorca earthquake, are characterized by brittle failures, as shown in the photographic documentation in Section 4.2. Thus, it is quite hard, also in the case of more accurate mechanical or numerical large scale vulnerability approaches (e.g., Borzi et al., 2008; Manfredi et al., 2012), to provide an estimate of such kind of failures. The latter aspect represents a challenging issue for vulnerability approaches in general, since brittle failures are often one of the most evident weaknesses of existing buildings (e.g., De Luca and Verderame, 2013). It is worth to note that also in the case of "grade 2" and "grade 3" there is a description of damage that involves both infills and RC elements.

The approximate nature of FAST and the fact it is based on a nonlinear static approach, in analogy with most of vulnerability approaches available in literature, prevent any reliable evaluation of cumulative damage. On the other hand, the conservative nature of the basic hypotheses of the methodology allows carrying out reliable results even in the case in which mainshock event succeeds quite significant foreshock events; as it was shown in the case of Lorca earthquake. 


\section{CONCLUSIONS}

An approximate explanation of the damage observed in RC structures during the $11^{\text {th }}$ May 2011 Lorca earthquake was carried out, based on spectral large scale considerations and through FAST method. Special features of ground motion and characteristics of the building stock in the region, as a consequence of seismic code provisions and construction practice have been taken into account. The analysis of ground motion emphasized that the event was stronger if compared to typical code benchmarks. Directivity effects were observed in fault normal direction, causing non-homogeneous effects in the near-source region in which the city of Lorca is located.

No proper seismic structural conception was found in most of Lorca RC buildings, because of construction practice and because of Spanish old seismic codes lacks. The lack of capacity design and the interaction with masonry infill panels caused frequent brittle failures in columns. However, despite the unfavorable conditions of both event and structural features, global collapses were rarely observed. Thanks to damage data classified according to EMS98 after the earthquake, it was possible to observe that buildings showed frequently a grade 2 damage state (DS2). DS2 is characterized by moderate damage (nonstructural damage) that mostly involves infills.

Damage assessment, through $F A S T$, emphasized how masonry infills provided additional, "not designed", strength to RC structures. This methodology is based on static pushover analysis. A simplified capacity curve of uniformly infilled reinforced concrete moment resisting frames is defined and mechanical-experimental interpretation of damage states, defined according to EMS98 scale, allows the definition of peak ground acceleration (PGA) thresholds for each damage state, as function of the acceleration spectra of the recorded ground motion. PGA thresholds are obtained up to grade 3 of EMS98 scale, because FAST method is based on infill damage that rules only the first three damage states of the scale.

A fair to good agreement was found in terms of comparison of the observed damage data versus the analytical prediction made through FAST. Trends with number of storeys and design codes are captured with quite good accuracy considering the large scale approach employed. In fact, FAST is conceived for rapid decision making environments; such as the basic damage mapping in the phase of emergency management right after seismic events or in post-emergency priority analyses for preliminary interventions. 


\section{ACKNOWLEDGEMENTS}

The work presented has been developed in cooperation with Rete dei Laboratori Universitari di Ingegneria Sismica - ReLUIS - Linea 1.1.2. for the research program funded by the Dipartimento della Protezione Civile (2010-2013).

\section{REFERENCES}

Alarcón, E., Astiz, M.A., Benito, M.B., Álvarez, R., Maeso, O., Bernal, A., Hermanns, L., 2010. Informe final sobre [...] la propuesta del anexo nacional español a la norma europea en 1998 (Eurocódigo 8), Ref: CMM_IGN_0210. Centro de Modelado en Ingeniería Mecánica.

American Society of Civil Engineers (ASCE), Seismic Rehabilitation of Existing Buildings, ASCE/SEI 41-06, Reston, Virginia, 2007.

ATC-40 (1996). Seismic evaluation and retrofit of concrete buildings. Applied Technology Council (ATC). Redwood City, California.

ATC3-06. Tentative provisions for the development of seismic regulations for buildings.Report No. ATC3-06, Applied Technology Council, Palo Alto, CA, 1978.

Baker, J.W. (2007). Quantitative classification of near-fault ground motions using wavelet analysis. Bulletin of the Seismological Society of America 97, 1486-1501.

Benavent-Climent A., Akiyama H., Lopez-Almansa F., Pujades L.G. (2004). Prediction of ultimate earthquake resistance of gravity-load designed RC buildings. Engineering Structures 26, 1103-1113.

Benavent-Climent A., (2007). Seismic behavior of RC wide beam-column connections under dynamic loading, Journal of Earthquake Engineering, 11, 493-511.

Benavent-Climent A., Cahìs X., Catalàn A., (2008). Seismic behavior of interior connections in existing waffle-flat-plate structures. Engineering Structures,30, 2510-2516.

Biskinis DE, Roupakias GK, Fardis MN., (2004). Degradation of shear strength of reinforced concrete members with inelastic cyclic displacement, ACI Structural Journal, 101, 773-783.

Borzi B., Elnashai A. (2000). Refined force reduction factor for seismic design. Engineering Structures $22,1244-1260$.

Borzi B., Pinho R., Crowley H., (2008). Simplified pushover-based vulnerability analysis for large scale assessment of RC buildings. Engineering Structures, 30(3), 804-820.

Cabañas, L., Carreño, E., Izquierdo, A., Martínez, J.M., Capote, R., Martínez, J., Benito, B., Gaspar, J., Rivas, A., García, J., Pérez, R., Rodríguez, M.A., Murphy, P. (2011). Informe del sismo de Lorca del 11 de mayo de 2011. IGN, UCM, UPM, IGME, AEIS. http://www.ign.es/ign/resources/sismologia/Lorca.pdf

Calconsa XXI (2011). Photographic report of the building "Menorca", Avda. de las Fuerzas Armadas, 2830-32, 30800 Lorca (Murcia), Spain. www.calconsa.com

CEN (2004) Eurocode 8: design of structures for earthquake resistance-Part 1: general rules, seismic actions and rules for buildings. European Standard EN 1998-1:2003- Comité Européen de Normaliation, Brussels.

CEN (2005) Eurocode 8: design of structures for earthquake resistance-Part 3: assessment and retrofitting of buildings, European Standard EN 1998-1:2005- Comité Européen de Normaliation, Brussels. 
Chioccarelli, E., De Luca, F., Iervolino, I. (2009). Preliminary study on L'Aquila earthquake ground motion records, V5.20. http://www.reluis.it/

Chopra, A.K. (2007). Dynamics of the Structures, Prentice Hall, Upper Saddle River, New Yersey, 3rd edition.

Colangelo F. (2012). A simple model to include fuzziness in the seismic fragility curve and relevant effect compared with randomness. Earthquake Engineering and Structural Dynamics, 41, 969-986.

Cornell, C.A. and Krawinkler, H. , 2000. Progress and challenges in seismic performance assessment. PEER News, April 2000.

Crowley H., Pinho R., (2010). Revisiting Eurocode 8 formulae for periods of vibration and their employment in linear seismic analysis. Earthquake Engineering and Structural Dynamics, 39(2), 223235.

CS.LL.PP.; 2009: Istruzioni per l'applicazione delle norme tecniche delle costruzioni. Gazzetta Ufficiale della Repubblica Italiana, 47. (in Italian).

De Luca, F. (2012). Records, capacity curve fits and reinforced concrete damage states within a performance based earthquake engineering framework. Ph.D. Thesis. University of Naples Federico II, Naples, Italy. Available at http://wpage.unina.it/flavia.deluca/outreach.htm

De Luca, F., Verderame, G.M. (2013). A practice-oriented approach for the assessment of brittle failures in existing RC elements, Engineering Structures 48, 373-388.

De Luca F., Vamvatsikos D., Iervolino I., (2013). Near-optimal piecewise linear fits of static pushover capacity curves for equivalent SDOF analysis, Earthquake Engineering and Structural Dynamics, 42(4), 523-543.

Dolce M., Cardone D., Ponzo F.C., Valente C., (2005). Shaking table tests on reinforced concrete frames without and with passive control systems. Earthquake Engineering and Structural Dynamics, 34, 1687-1717.

Dolšek, M., Fajfar, P. (2001). Soft storey effects in uniformly infilled reinforced concrete frames. Journal of Earthquake Engineering 5(1), 1-12.

Dolšek, M., Fajfar, P. (2004). Inelastic spectra for infilled reinforced concrete frames. Earthquake Engineering and Structural Dynamics 33,1395-1416.

Dolšek, M., Fajfar, P. (2005). Simplified non-linear seismic analysis of infilled reinforced concrete frames. Earthquake engineering and Structural Dynamics 34,49-66.

Dolšek, M., Fajfar, P. (2008). The effect of masonry infills on the seismic response of a four storey reinforced concrete frame - a probabilistic assessment. Engineering Structures 30(11), 3186-3192.

EHE (1999). Instrucción de hormigón estructural, Comisión permanente del hormigón estructural, Ministerio de Fomento, Madrid.

EHE-08 (2008). Instrucción de hormigón estructural, Comisión permanente del hormigón estructural, Ministerio de Fomento, Madrid.

Enomoto, T., Schmitz, M., Abeki, N., Masaki, K., Navarro, M., Rocavado, V., Sanchez, A. (2000) Seismic risk assessment using soil dynamics in Caracas, Venezuela. Proceedings of the $12^{\text {th }}$ World Conference on Earthquake Engineering, Auckland, New Zeland.

Erdik M., Durukal E., Siyahi B., Fahjan Y., Sesetyan K., Demircioglu M., Akman H., (2004). Earthquake risk mitigation in Istanbul. Chapter 7. IN: Mulargia F. And Geller R.J. Editors, Earthquake science and seismic risk reduction. Kluwer. 
Fajfar P. (1999). Capacity spectrum method based on inelastic demand spectra. Earthquake Engineering and Structural Dynamics, 28, 979-993.

Fardis M.N., 1997. Experimental and numerical investigations on the seismic response of RC infilled frames and recommendations for code provisions. Report ECOEST-PREC8 No 6. Prenormative research in support of Eurocode 8.

Fardis M.N., 2009. Seismic design, assessment and retrofitting of concrete buildings based on ENEurocode 8. Springer, August.

FEMA. NEHRP recommended provisions for seismic regulations for new buildings. FEMA 273, Federal Emergency Management Agency, Washington, DC, 1994.

Feriche M., y Equipo de Trabajo del IAGPDS, (2011). Efectos del Terremoto de Lorca en las edificaciones. Available at http://www.ugr.es/ iag/lorca/Efecto edificaciones.pdf, (last accessed 032013).

Feriche M., Vidal F., Alguacil G., Navarro M., Aranda C. Vulnerabilidad y daño en el terremoto de Lorca de 2011 (2012). $7^{a}$ Asamblea hispano-portuguesa de Geodesia y Geofísica. San Sebastián, 25-29 de junio de 2012

Galasso C., Cosenza E., Maddaloni G. (2010). Statistical analysis of reinforcing steel properties for seismic design of RC structures. Proceedings of the 14th European Conference on Earthquake Engineering, August 30-September 3, Ohrid, Republic of Macedonia.

Galasso C., Cosenza E., Maddaloni G. (2013). Uncertainty analysis of flexural overstrength for new designed RC beams, ASCE Journal of Structural Engineering (under review).

Goretti A.. and Di Pasquale G., (2006). Technical emergency management. In: Oliveira C.S., Roca A., and Goula X. Editors; Assessing and managing earthquake risk, Springer, chapter 16.

Grunthal G (editor) (1998). European Macroseismic Scale 1998. Cahiers du Centre Europeen de Geodynamique et de Seismologie, 7, Luxembourg, 99p.

Iervolino I., De Luca F., Cosenza E., (2010). Spectral shape-based assessment of SDOF nonlinear response to real, adjusted and artificial accelerograms, Engineering Structures, 32, 2776-2792.

IGN (2011): Seismic catalog: database. Service of seismic information.

Kalkan E., Kunnath S.K., (2008). Relevance of absolute and relative energy content in seismic evaluation of structures, Advances in Structural Engineering, 11, 1-18.

Kircher C.A., Nassar A.A:, Kutsu O., Holmes W.T., (1997). Development of building damage functions for earthquake loss estimation. Earthquake Spectra, 13(4), 663-681.

Kobayashi H, Vidal F, Feriche D, Samano T, Alguacil G., (1996). Evaluation of dynamic behavior of building structures with microtremors for seismic microzonation mapping. Proceedings of the $11^{\text {th }}$ World Conference on Earthquake Engineering, Acapulco, Mexico Paper 1769.

Krawinkler H. and Miranda E., 2004. Performance-Based Earthquake Engneering. In: Bozorgnia Y. and Bertero V.V. Editors Earthquake Engineering: From engineering seismology to performance-based engineering, CRC Press, chapter 9.

Lam, N., Wilson, J., Adrian Chandler, A., Hutchinson, G., (2000). Response spectrum modelling for rock sites in low and moderate seismicity regions combining velocity, displacement and acceleration predictions Earthquake engineering and structural dynamics 29,1491-1525.

Mainstone R.J., (1970). On the stiffnesses and strengths of infilled frames, Proceedings of the Institution of Civil Engineering, Supplement IV, 57-90. 
Manfredi, G. (2001). Evaluation of seismic energy demand. Earthquake Engineering and Structural Dynamics 30,485-499.

Manfredi G., Ricci P., Verderame G.M. (2012), Influence of Infill Panels and Their Distribution on Seismic Behavior of Existing Reinforced Concrete Buildings, The Open Construction and Building Technology Journal, 2012, 6, (Suppl 1-M1).

Manfredi G., Verderame G.M., Prota A., Ricci P., De Luca F., (2013), 2012 Emilia earthquake, Italy: Reinforced Concrete buildings response, Bulletin of Earthquake Engineering (under review).

Mezcua, J., Rueda, J., García, R.M. (2011). A new probabilistic seismic hazard study of Spain. Natural Hazards 59,1087-1108

MV 101 (1963). Acciones en la edificación, BOE No 35, Madrid.

Navarro M., Sànchez F.J., Feriche M., Vidal F., Enomoto T., Iwatate T., Matsuda I., Maeda T., (2002). Statistical estimation for dynamic characteristics of existing buildings in Granada, Spain, using microtremors. Structural Dynamics, Eurodyn 2002, I, 807-812, Balkema.

Navarro M, Oliveira CS (2004) Evaluation of dynamic characteristics of reinforced concrete buildings in the City of Lisbon. 4th Assembly of the Portuguese-Spanish of Geodesy and Geophysics, Figueira da Foz, Portugal.

Navarro M., Garcìa-Jerez A., Alcalà F.J., Vidal F., Aranda C., Enomoto T., (2012). Analysis of site effects, building response and damage distribution observed due to the 2011 Lorca, Spain, earthquake. Proceedings of the $15^{\text {th }}$ World Conference on Earthquake Engineering, Lisbon, Portugal.

NCSE-02 (2002). Norma de construcción sismorresistente, BOE N²44, Madrid.

NCSR-94 (1995). Norma de construcción sismorresistente, BOE Nº 33, Madrid.

NIBS, National Institute of Building Science (1997, 1999 and 2002). Earthquake loss estimation methodology. HAZUS. Technical manuals. Federal Emergency Management Agency (FEMA), Washington, Vol. 1, 2, 3. (http://www.fema.gov/hazus/).

Oliveira CS (2004) Actualização das bases-de-dados sobre frequências próprias de estruturas de edifícios, pontes, viadutos e passagens de peões a partir de medições expeditas in-situ. 5th Portuguese Conference on Earthquake Engineering, University of Minho, Guimarães (in Portuguese).

Oliveira CS, Navarro M., (2010) Fundamental periods of vibration of RC buildings in Portugal from insitu experimental and numerical techniques. Bulletin of Earthquake Engineering, 8(3), 609-42.

PDS-1 Parte A (1974). Norma sismorresistente, BOE N² 279, Madrid.

PGS-1 Parte A (1968). Norma sismorresistente, BOE Nº 30, Madrid.

Regalado, F., Lloret, V. (2011). Análisis y reflexiones sobre los terremotos del 11 de mayo del 2011 acontecidos en Lorca (sugerencias para el futuro). FR\&A.

Ricci, P., De Luca, F., Verderame, G.M. (2011a). 6th April 2009 L'Aquila earthquake, Italy - Reinforced concrete building performance. Bulletin of Earthquake Engineering 9(1),285-305.

Ricci, P., Verderame, G.M., Manfredi, G., Pollino, M., Borfecchia, F., De Cecco, L., Martini, S., Pascale, C., Ristoratore, E., James, V. (2011b). Seismic vulnerability assessment using field survey and Remote Sensing techniques. In: B. Murgante, O. Gervasi, A. Iglesias, D. Taniar, B.O. Apduhan (editors). Computational Science and its Applications - ICCSA 2011. Springer-Verlag Berlin Heidelberg, 2011.

Ricci, P., Verderame G.M., Manfredi G., (2011c) Analytical investigation of elastic period of infilled RC MRF buildings, Engineering Structures 33(2), 308-319. 
Rossetto, T., Peiris, N. (2009). Observations of damage due to the Kashmir earthquake of October 8, 2005 and study of current seismic provisions for buildings in Pakistan. Bulletin of Earthquake Engineering, 7(3): 681-699.

Sezen, H., Moehle, J.P. (2004). Shear strength model for lightly reinforced concrete columns. ASCE Journal of Structural Engineering 130(11), 1692-1703.

Uang C., Bertero V.V., (1990). Evaluation of seismic Energy in structures. Earthquake Engineering and Structural Dynamics, 19, 77-90.

Verderame GM, De Luca F, Ricci P, Manfredi G. (2011). Preliminary analysis of a soft-storey mechanism after the 2009 L'Aquila earthquake. Earthquake Engineering and Structural Dynamics, 40(8), 925 944.

Verderame G.M., De Luca F., De Risi M.T., Del Gaudio C., Ricci P., (2012). A three level vulnerability approach for the damage assessment of infilled RC buildings: the Emilia 2012 case, V1.0, available at http://www.reluis.it/.

Verderame G.M., Ricci P., De Luca F., Del Gaudio C., De Risi M.T., (2013). Damage scenarios for RC buildings during the 2012 Emilia (Italy) earthquake. Soil Dynamics and Earthquake Engineering (under review).

Vidal, F., Alguacil, G., Feriche, M., Aranda, C., Morales, J., Stich, D., Pérez Muelas, J., Benito, J., López, J.M. (2011). El terremoto de Lorca: Mayo 2011. Causas del impacto y primeras medidas. Análisis preliminar. Informe IAGPDS, Universidad de Granada. http://www.ugr.es/ iag/lorca/Impacto_Lorca.pdf

Vidic, T., Fajfar, P., Fischinger, M. (1994). Consistent inelastic design spectra: strength and displacement. Earthquake engineering and structural dynamics 23,502-521.

Vielma, J.C., Barbat, A.H., Oller, S. (2010). Seismic safety of low ductility structures used in Spain. Bulletin of earthquake engineering 8,135-155.

VV.AA. (2006): Riesgo Sísmico de la Comunidad Autónoma de la Región de Murcia (RISMUR). 6 Vols. Instituto Geográfico Nacional y Dirección General de Protección Civil CARM. 